\title{
EMANCIPACIÓN JUVENIL Y POLÍTICAS DE VIVIENDA EN EUROPA
}

\author{
Juan Manuel Patón Casas ${ }^{1}$ \\ Servei Municipal d'Ocupació \\ Ajuntament de Tarragona
}

\section{Remisión artículo: 17/09/2007}

Palabras clave: emancipación juvenil, transiciones juveniles, políticas de juventud, políticas de vivienda, independencia residencial, políticas de transición, políticas afirmativas, abandono del hogar familiar de origen, independización residencial.

Resumen: El principal objetivo de este artículo es explorar el peso relativo de las políticas de vivienda en los procesos de emancipación y transición juvenil, centrando la atención sobre las edades a las que se produce la independización residencial de los jóvenes en diferentes países europeos. El artículo somete a discusión algunas de las cuestiones clave, prestando simultáneamente atención a las dimensiones objetiva y subjetiva del proceso de emancipación y destacando su relación mutua. Así, el artículo defiende la importancia central de la ampliación del marco de oportunidades, enfatizando el papel que el sistema de bienestar juega en la definición de las expectativas juveniles. No obstante, se defiende también la posibilidad de que un desarrollo autónomo de las diversas áreas de política social -y de las políticas de vivienda en particular- contribuya a la definición de las actitudes y las predisposiciones culturales de los jóvenes, tanto en lo que se refiere a la independización residencial como en cuanto tiene que ver con el proceso de formación familiar. El artículo discurre mediante el recurso a referencias bibliográficas clave -la mayoría de ellas disponibles en línea para su consulta- y la utilización, cuando ha sido necesario, de datos estadísticos de carácter secundario.

Estructura del artículo: En primer lugar, a modo introductorio, el articulo discute la importancia relativa de las predisposiciones culturales frente a los factores institucionales y las políticas públicas. En segundo lugar, se considera el peso relativo de los sistemas de bienestar globalmente considerados- sobre los procesos de emancipación juvenil. En tercer lugar, se explora el contexto de política social en que la emancipación juvenil tiene lugar, destacando el papel de determinadas áreas clave que, combinadas entre sí, facilitan una aproximación integral tanto al conjunto de las necesidades juveniles transicionales como a la ampliación de las oportunidades de emancipación residencial. En cuarto lugar, se ofrecen argumentos que justifican la posibilidad de desarrollar las políticas de vivenda con relativa autonomía respecto del marco general ofrecido por sistema de bienestar. En quinto lugar, se procede a destacar las cuestiones clave que, en lo que se refiere a políticas de vivienda, han de ser tomadas en consideración -atendiendo tanto a las demandas explícitas como a las expectativas implícitassi se pretende promover el acceso a la independencia residencial a la vez que la autonomía real de los jóvenes. Estas cuestiones clave son las alternativas de tenencia de la vivienda y la tipología de los inmuebles. Finalmente, el artículo sugiere algunos argumentos que podrían

\footnotetext{
${ }^{1}$ Persona de contacto Juan Manuel Patón, correo: paton.joventut@tinet.org
} 
cuestionar la conveniencia de focalizar políticas de vivienda directa y específicamente sobre los jóvenes, frente a una aproximación de carácter universal que implique el desarrollo de dichas políticas sin concentrar los esfuerzos en una determinada categoría de edad o grupo social.

\section{Introducción: Factores objetivos y subjetivos en los procesos de emancipación}

Las transiciones juveniles pueden ser observadas desde dos puntos de vista complementarios y sin duda interrelacionados. Por un lado, los condicionantes objetivos -los contextos familiares, sociales y económicos- establecen las posibilidades materiales -objetivas, puespara el acceso de los jóvenes al ejercicio de sus derechos de ciudadanía. Pero, por otro lado, las transiciones juveniles son también determinadas por las decisiones que los jóvenes adoptan en cuanto a la asunción individual de responsabilidades. Así pues, cuando hablamos de factores "objetivos", nos estamos refiriendo a aquellos que determinan y configuran el marco general de oportunidades. Y cuando hablamos de factores "subjetivos", aludimos a los que tienen que ver con las actitudes adoptadas por los propios jóvenes a partir de un determinado universo de expectativas y predisposiciones culturales

La emancipación juvenil -en la que la independización residencial juega un papel clave- debe ser entendida y abordada como un proceso complejo en el que los factores objetivos se entrecruzan con otros de carácter subjetivo a que hemos aludido en el párrafo anterior. Así, si ninguna aproximación por sí sola nos explica las diferencias observables en Europa -tal y como argumenta Billari (2004)- nos parece clara la necesidad de atender a los dos conjuntos de factores -objetivos y subjetivos; si se quiere:, materiales y culturales- que están implicados en los procesos de emancipación juvenil y que, a su vez, se condicionan mutuamente.

El problema reside en establecer -al menos a nivel de hipótesis- el peso relativo de cada uno de estos dos conjuntos de factores, así como la manera en que se interrelacionan. Nuestra hipótesis -que ha ya sido anteriormente apuntada por una gran parte de bibliografía de referencia- puede fácilmente derivarse de la observación de las condiciones de vida de las personas jóvenes, en relación con los diversos sistemas de bienestar y las políticas públicas y sociales que se desarrollan bajo su amparo. Defendemos, pues, que el conjunto de recursos materiales que se pone a disposición de los jóvenes incide determinantemente en la configuración de los elementos más básicos de sus predisposiciones culturales y de las de sus familias. En primer lugar, porque parece claro que las condiciones de orden material operan siempre como condición sine qua non para la emancipación, al definir el marco efectivo de oportunidades al alcance. En segundo lugar, porque los sistemas de bienestar-los esquemas institucionales y las políticas públicas- no sólo establecen los límites en cuanto a las posibilidades materiales para la cobertura de las necesidades, sino que también contribuyen a definir el espacio en el que pueden surgir y desarrollarse expectativas que se refieren a los modos alternativos de satisfacción (Patón Casas, 2003)

Los diferentes contextos -familiares, sociales y económicos- y los diversos esquemas de bienestar -que establecen la distribución de responsabilidades entre el estado, la familia y el mercado en orden a la satisfacción de las necesidades sociales- son, pues, determinantes en los procesos de emancipación juvenil. Y disponemos de argumentos suficientes para defender que la heterogeneidad observable en los diferentes países en cuanto a las experiencias transicionales de los jóvenes -en particular, la edad de emacipación- depende más del conjunto de variables sociales y económicas $-\mathrm{y}$, sobre todo, institucionales- que de las 
predisposiciones culturales y las orientaciones actitudinales previas de los jóvenes o de sus familias. En todo caso -e independientemente del peso relativo que se les quiera otorgar- éstas últimas se verán siempre afectadas y modificadas de manera substancial -probablemente, sin embargo, en el medio o el largo plazo- por el resultado de la variación en el abanico de oportunidades materiales, esto es, por el resultado de la distribución y redistribución de responsabilidades en el sistema de bienestar.

Corijin (1999) se ha referido, por ejemplo, al hecho de que un alargamiento del período educativo-formativo a tiempo completo puede haber contribuido, en muchos casos, a la posposición del abandono del hogar familiar de origen. Los factores que pueden dar lugar a este fenómeno son muy diversos y efectivamente tienen que ver con las predisposiciones culturales relativas a la idea de familia. Pero guarda también relación con las diferencias socioeconómicas, con la existencia o no de alojamiento para estudiantes, con la accesibilidad de la vivienda o con la distribución geográfica de las instituciones educativas -esto es, con factores de orden objetivo que en gran medida dependen de la intervención pública. Así, aún cuando centremos nuestra atención en las orientaciones actitudinales de los jóvenes, un retardo en el proceso de emancipación que se pueda dar como resultado de la decisión de extender el período vital dedicado a la educación y la formación -es decir, tomar la decisión de permanecer en el hogar familiar de origen mientras se cursan estudios medios o superiores- no puede ser evaluado de la misma manera que aquél otro que se produzca como derivación de dificultades objetivas de orden material, puesto que éstas operan como obstáculo para la autonomía en la toma de decisiones (Patón Casas, 2003). De hecho, Corijin nos muestra cómo, aún cuando el alargamiento del período formativo contribuye de hecho -generalmente y en toda Europa- a retardar el abandono del hogar familiar de origen, el caso de Holanda constituye una excepción, probablemente como derivación del hecho de que -al menos hasta 1990- este país proporcionó un apoyo determinante a los estudiantes.

Parece bastante claro, pues, que la decisión de alargar el período dedicado a la educación y la formación no tiene porqué comportar ineludiblemente la necesidad de posponer el abandono del hogar familiar de origen, en particular si se dispone de los medios necesarios para iniciar el proceso de emancipación recurriendo, por ejemplo, a las residencias estudiantiles. Difícilmente podrá establecerse que las decisiones individuales se toman exclusiva $-\mathrm{y}$ ni si quiera fundamentalmente- en base a predisposiciones culturales previas, dado que las oportunidades al alcance -esto es, las alternativas posibles- contribuyen a definir del imaginario de los jóvenes y inciden también, pues, en el fortalecimiento -o el debilitamiento- de eventuales predisposiciones tendencialmente autolimitantes. Otro ejemplo claro lo constituye la supuesta mayor propensión de los (jóvenes) españoles hacia la propiedad de la vivienda o la mayor propensión de los (jóvenes) europeos hacia la tenencia en régimen de alquiler. De hecho, para el caso particular de España parece claro que el sentido de estas tomas de decisión "individuales" es consecuencia de unos sistemas de orientación de la oferta inmobiliaria que no ha dejado lugar a la elección entre formas alternativas de tenencia de la vivienda (Trilla, 2001).

Es bien cierto que los sistemas de bienestar europeos no pueden ser interpretados como puramente exógenos, puesto que -al menos en parte- se han configurado a partir de factores culturales y dependencias históricas - path dependencies (Aassve et al., 2001). Sin embargo, incluso cuando hagamos referencia a la dimensión social de las predisposiciones culturales -a la herencia cultural de las sociedades y los países- deberemos de tener en cuenta que, si bien es cierto que el marco institucional recibe el impacto de tradiciones arraigadas, a su vez el régimen de bienestar puede ser decisivo en la definición social agregada del marco de 
oportunidades al alcance, así como en el desarrollo del universo de expectativas juveniles y, por lo tanto, también en la redefinición de las predisposiciones culturales y actitudinales de los jóvenes.

Así, pues, partiendo de la emancipación juvenil como un fenómeno sociodemográfico complejo, en el que las predisposiciones culturales juegan sin duda algún papel, optaremos aquí por referirnos a los factores objetivos que vienen a determinar las oportunidades de emancipación, situando así el centro de nuestras reflexiones en los obstáculos y barreras de orden material. Barreras y obstáculos que restringen la capacidad de optar por unos $u$ otros cursos alternativos de acción y dificultan, pues, el desarrollo de unos $u$ otros universos de expectativas en unos $u$ otros contextos institucionales y sociales. Es cierto que ante un mismo marco de oportunidades y ante el impacto de un mismo conjunto factores condicionantes de tipo objetivo -esto es, ante un mismo abanico de posibilidades- los jóvenes pueden llegar a tomar decisiones en extremo divergentes. Pero también lo es que el conjunto de los recursos que los gobiernos puedan dedicar -y las medidas que puedan articular- para atender las necesidades de los jóvenes y para eliminar las barreras y los obstáculos que dificultan la ampliación de sus expectativas, serán siempre un elemento clave a tener en cuenta. Así, por ejemplo, claramente no puede afirmarse que el acceso a la vivienda sea una condición suficiente -en exclusiva y en todos los contextos- para la emancipación juvenil o la independización residencial. Pero parece bastante obvio que el acceso a la vivienda, no sólo opera como una condición necesaria para la propia emancipación, sino que tenderá a promover -en general y en comunión con otros factores- un adelantamiento en la edad a partir de la cual se abandona el hogar familiar de origen en uno $u$ otro país, facilitando así una ampliación simultánea del espacio de autonomía a disposición de los jóvenes.

\section{Transiciones juveniles, emancipación y sistemas de bienestar}

La sociología y los estudios sociodemográficos más actuales nos hablan de una tendencia general -común en toda Europa- hacia ampliación de la etapa juvenil en la vida de las personas, así como de un retardo el momento en que los jóvenes deciden abandonar el hogar familiar de origen. La Tabla 1 nos muestra cómo, entre 1995 y 1997, los jóvenes experimentaron este retraso en todos los países tomados en consideración, con la única excepción del caso particular de Finlandia.

Sin embargo, no parece que los datos apunten hacia un proceso generalizado de convergencia, puesto que ni todos los países parten del mismo punto, ni el retardo ha sido igual de significativo en cada uno de ellos, ni la velocidad a la que se produce la emancipación es uniforme, ni la emancipación presenta un grado similar de estandarización (Billari y Wilson, 2001). Se puede apuntar, además, que la heterogeneidad tenderá previsiblemente a persistir pese a las tendencias derivadas del proceso de globalización, puesto su impacto sobre las trayectorias vitales depende en gran medida de las configuraciones institucionales y de la economía política de los diferentes países (Mayer, 2001). Podemos a continuación, pues, examinar la existencia de correlaciones que nos permitan a identificar condicionantes comunes en unos $u$ otros países y ofrecer, así, alguna interpretación plausible en cuanto a la variabilidad observable. Avanzamos nuestra propuesta de considerar la centralidad de los sistemas de bienestar, tal y como se ha sugerido en el apartado introductorio. 
Tabla 1. Indicadores de emancipación juvenil en diversos países europeos (diversas fuentes)

\begin{tabular}{|c|c|c|c|c|c|c|c|c|c|c|}
\hline & \multicolumn{2}{|c|}{ IARD (1) } & \multicolumn{2}{|c|}{ BILLARI (2) } & \multicolumn{6}{|c|}{ BILLARI (3) } \\
\hline & \multirow[b]{2}{*}{ 品 } & \multirow[b]{2}{*}{ 녹 } & \multirow[b]{2}{*}{ 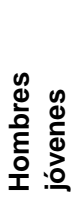 } & \multirow[b]{2}{*}{ 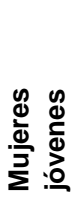 } & \multicolumn{3}{|c|}{ Hombres jóvenes } & \multicolumn{3}{|c|}{ Mujeres jóvenes } \\
\hline & & & & & 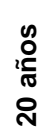 & $\begin{array}{l}\text { ஜ } \\
\text { ટ્ટ } \\
\text { సี }\end{array}$ & 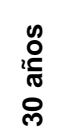 & 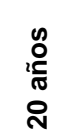 & 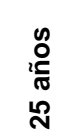 & 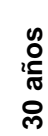 \\
\hline HOL & 55 & 47 & 22,5 & 20,5 & 75 & 25 & 5 & 57 & 10 & 2 \\
\hline AL1* & nd & nd & 22,4 & 20,7 & 74 & 26,5 & 9,5 & 58,5 & 13,5 & 4 \\
\hline AUS & nd & 65 & 21,8 & 19,9 & 67 & 30 & 16 & 48 & 15 & 6 \\
\hline SUE & nd & nd & 20,2 & 18,6 & 52 & 7 & 2 & 25 & 2 & 1 \\
\hline RU & 45 & 47 & 22,4 & 20,3 & 73 & 28 & 11 & 55 & 13 & 5 \\
\hline NOR & nd & nd & 21,4 & 19,8 & 66 & 19 & 1 & 45 & 7 & 1 \\
\hline FRA & 47 & 52 & 21,5 & 19,8 & 68 & 20 & 9 & 47 & 15 & 5 \\
\hline FIN & nd & 29 & 21,7 & 19,8 & 68 & 23 & 12 & 45 & 7 & 2 \\
\hline IRL & 64 & 64 & nd & nd & nd & nd & nd & nd & nd & $\overline{\mathrm{nd}}$ \\
\hline AL2** & 57 & 55 & 22,4 & 20,8 & 76 & 30 & 11 & 59 & 14 & 4 \\
\hline BEL & 63 & 68 & 23,3 & 21,5 & 87 & 31 & 11 & 70 & 13 & 4 \\
\hline ITA & 81 & 87 & 26,7 & 23,6 & 87 & 61 & 32 & 78 & 39 & 20 \\
\hline POR & 75 & 82 & 24,3 & 21,8 & 79 & 44 & 26 & 63 & 30 & 19 \\
\hline SUI & nd & nd & 21,5 & 19,2 & 66 & 20 & 3 & 38 & 6 & 1 \\
\hline LUX & 64 & 69 & nd & nd & nd & nd & nd & nd & nd & $\overline{\mathrm{nd}}$ \\
\hline ESP & 84 & 89 & 25,7 & 22,9 & 86 & 54 & 25 & 76 & 33 & 14 \\
\hline GRE & 63 & 72 & nd & nd & nd & nd & nd & nd & $\mathrm{nd}$ & $\mathrm{nd}$ \\
\hline
\end{tabular}

Elaboración propia a partir de diversas fuentes (vid. infra). La coloración del cuadro pretende facilitar la identificación de correlaciones. * AL1: Alemania integrada / ** AL2: Alemania Occidental (antigua RFA).

(1) Porcentaje de jóvenes entre 20 y 24 años que permanecen en el hogar familiar de origen. 1995: Cohortes nacidas entre1970 y 1975. Datos de Eurostat (1997). Fuente: IARD (2001), Vol. 1: 45 (extracto)

(2) Edad mediana a la que los jóvenes abandonan el hogar de origen. Cohortes nacidas hacia 1960. Fuente: BILLARI (2001): 28 (extracto)

(3) Porcentaje de jóvenes de que a los 20, 25 y 30 años de edad todavía no han abandonado el hogar familiar de origen. Fuente: BILLARI (2001): 29 (extracto)

Billari (2004) analiza correlaciones entre países en cuanto se refiere al sistema de bienestar y los marcos institucionales. Propone tener en cuenta la modelización de los sistemas de bienestar propuesta por Esping Andersen (1993) y otros autores (Leibfried, 1992, Barlow y Duncan, 1994, Ferrara, 1996), distinguiendo entre el sistema de bienestar socialdemócrata característico de los países nórdicos; el sistema liberal de mercado característico de los países anglosajones; el sistema conservador de la Europa continental; y, adicionalmente, el sistema familiarista que es característico de los países del sur de Europa y que no fue contemplado por Esping Andersen como modelo independiente. En relativa correspondencia con esta modelización, Billari identifica dos patrones generales, que permiten establecer una distinción entre el caso extremo de los países en los que los jóvenes se emancipan más temprano y el de los países en que los jóvenes se emancipan más tarde. El primer patrón se corresponde con los países del sur de Europa, en los que la emancipación tiende a seguir una pauta estandarizada en relación con la formación de la familia -independencia residencial generalmente vinculada al matrimonio- pero desestandarizada en cuanto al momento en que los jóvenes abandonan el hogar familiar de origen. El segundo patrón se corresponde con los países nórdicos, en los que la emancipación juvenil se produce estandarizadamente entre los 19/20 años, pero en los que la salida del hogar de origen conduce a una mayor heterogeneidad 
de formas de vida y convivencia. Una primera clasificación de países nos permite, pues, distinguir entre aquellos en que la emancipación juvenil es mucho más lenta y tardía y aquellos otros en los que es claramente más rápida y temprana (Billari, 2004). La Tabla 1 servirá de apoyo a los argumentos que siguen.

En cuanto al primer conjunto de países, caracterizados por una emancipación juvenil mucho más lenta y tardía, nos referiremos aquí a Portugal, España, Italia y también a Grecia, aunque no disponemos de datos completos para éste último caso. A este respecto, la Tabla 1 nos muestra lo siguiente:

- Que en estos países la mediana de edad a la que los varones jóvenes abandonan el hogar familiar de origen se sitúa por encima de los 24 años, destacando aquí el caso particular de Italia donde esta edad se sitúa cerca de los 27 . En cuanto a las mujeres, la edad de emancipación se sitúa en todos los casos alrededor de los 22-23 años.

- Que, tanto para 1987 como para 1997, estos países presentan un porcentaje de más del $70 \%$ de jóvenes entre los 20 y 24 años de edad que todavía viven con sus padres (Grecia deja de ser una excepción en 1995).

- Que sólo entre los jóvenes de 30 años el porcentaje de no emancipados se sitúa en estos países por debajo del 25-30\%. Si bien es cierto que las mujeres jóvenes no emancipadas a los 30 años representan un porcentaje bastante menor que el de los hombres, hay que tener en cuenta que el hecho de superar el $10 \%$ las sitúa bastante por encima de lo que viene a ser común en Europa.

Por lo que respecta al segundo conjunto de países, caracterizados por una emancipación juvenil más rápida y temprana, destacaremos los casos de Suecia, Noruega, Finlandia, Suiza y -con algunas reservas- también a Francia, Holanda, Austria y la Alemania integrada. A este respecto, la Tabla 1 nos muestra lo siguiente:

- La edad mediana para la emancipación de las mujeres jóvenes es en todos estos países inferior a los 20 años, e inferior a los 22 en lo que respecta a los hombres.

- Tanto en 1987 como en 1995, estos países presentan un porcentaje inferior al 50\% de jóvenes de entre 20 y 24 años que todavía no se han emancipado, a excepción -para el año 1995- de Austria (65\%) y en menor medida Francia (52\%).

- Entre los varones jóvenes de 25 años el porcentaje de varones no emancipados se sitúa ya por debajo del 25\%, a excepción ahora también de Austria (30\%). Entre las mujeres de esta edad, el porcentaje de emancipadas se sitúa por debajo del $10 \%$ en los tres países nórdicos considerados (Suecia, Noruega y Finlandia), pero también en Suiza (6\%) y Holanda (10\%)

- Entre los jóvenes de 30 años de edad el porcentaje de varones no emancipados se sitúa, por debajo del $10 \%$ en dos de los tres países nórdicos (no así en Finlandia, donde todavía se observa un porcentaje del 12\%), en Suiza, en Holanda y en Francia y en la Alemania integrada. En el caso de las mujeres, el porcentaje se sitúa entre el 1 y el $2 \%$ tanto en los tres países nórdicos como también en Suiza y en Holanda. 
A la luz de estos datos, podemos remitirnos al modo en el que los diversos esquemas de bienestar establecen los patrones para la satisfacción de las necesidades sociales y al grado en los diversos sistemas promueven -o inhiben- la emancipación juvenil temprana. Generalmente, allí donde el estado de bienestar no ha desarrollado un sentimiento de responsabilidad pública sobre las necesidades transicionales de las personas jóvenes, son la familias las que acostumbran a hacerse cago de su satisfacción. Es bien conocido -y ha sido bien estudiado- el hecho de que la ausencia de derechos sociales garantizados en su ejercicio por el estado genera dinámicas culturales de sobreresponsabilización familiar ${ }^{2}$. Y es precisamente allí, donde el abanico de oportunidades ofrecido por el sistema de bienestar es más reducido, que la sociedad en su conjunto ha adoptado predisposiciones culturales favorables la asunción socialmente normalizada de las limitaciones en el ejercicio de los derechos sociales; predisposiciones culturales conducentes a inhibir, por lo tanto, el desarrollo de las aspiraciones de autonomía juvenil e independencia residencial. Así, la decisión de prolongar la permanencia en el hogar familiar de origen -en la mayor parte de los casos sin duda autolimitante- puede fundamentarse en condicionamientos y factores de tipo cultural, particularmente en países del área mediterránea como Italia o España. Pero, tal y como hemos argumentado en la introducción, debemos tender a pensar que estas actitudes son normalmente expresión y reflejo de limitaciones de carácter objetivo: de la estrechez del marco efectivo de oportunidades ofrecido por el sistema de bienestar y de las barreras que consiguientemente se interponen al desarrollo y la ampliación de las expectativas juveniles.

Claro está que sólo una ampliación en el marco de oportunidades de los jóvenes en un determinado país nos permitirá establecer el peso relativo de las predisposiciones culturales frente a las configuraciones institucionales. Sin embargo, el análisis transnacional nos habilita para apuntar algunas ideas al respecto. Así, en la anterior Tabla 1 podemos observar, muy nítidamente, cómo la emancipación juvenil más lenta y tardía se da precisamente en los países del área mediterránea, esto es, en los países donde el sistema de bienestar es fuertemente familiarista y en los que el grado de responsabilidad pública en la cobertura de necesidades sociales es mínimo. Y podemos observar también cómo los países nórdicos de tipo socialdemócrata -con un sistema de bienestar poderoso y basado en un alto grado de responsabilidad pública en la cobertura de necesidades sociales- presenta, en general y pese a las variaciones entre países, una emancipación juvenil mucho más rápida y temprana.

Se dan, por supuesto, casos intermedios en relación con esta norma general en función de la cual cabe destacar la centralidad de los sistemas de bienestar. Se trata de los casos de Suiza, Francia, Holanda, Austria y Alemania. Se trata de países que hemos clasificado junto a los nórdicos en razón de la relativa rapidez con que los jóvenes se independizan del hogar familiar de origen, aún siendo cierto que sus respectivos sistemas de bienestar no constituyen un modelo tan generoso en prestaciones sociales como lo es el nórdico. Y es que -por un lado, como veremos- la intervención mediante de las políticas públicas -económicas y fiscales, de familia, de vivienda o de mercado laboral- dispone de un cierto espacio para su desarrollo autónomo respecto del sistema de bienestar. Y cabe pues tener en cuenta el impacto

\footnotetext{
${ }^{2}$ Por supuesto, esto no ocurre sólo en cuanto se refiere a la emancipación juvenil. Así, cuando el estado no provee a la sociedad de servicios para dar cobertura a las necesidades de las personas mayores en situación de dependencia, son los hijos -las hijas, en realidad- quienes las asumen como responsabilidad (ética o moral) propia. Igualmente ocurre cuando, ante la ausencia de una adecuada oferta pública de escuelas 0-3 años, las madres se hacen cargo -a menudo en exclusiva- de las responsabilidades educativas a lo largo de las primeras etapas de vida de los niños. Y, a los efectos que aquí nos interesa, los padres y las madres -en este caso solidariamente- se hacen cargo de las necesidades de los jóvenes adultos en transición, permitiéndoles permanecer hasta edades muy avanzadas -e incluso indefinidamente- en el hogar familiar de origen.
} 
diferencial que el desarrollo de determinadas políticas económicas y sociales podrá tener, por sí mismo, en las oportunidades de emancipación de los jóvenes (Billari, 2004). A nosotros nos interesa analizar, por un lado, el impacto relativo de las políticas de vivienda sobre las oportunidades de abandono del hogar familiar de origen. Y, por otro, debemos analizar también qué otras políticas acompañan y coadyuvan a las de vivienda en orden a facilitar las transiciones juveniles y promover la emancipación temprana. Comenzaremos con estas últimas para seguir después con las políticas de vivienda propiamente dichas.

\section{Transiciones juveniles, emancipación y políticas sociales}

Siguiendo de nuevo a Corijin (1999) y adoptando, por tanto, una perspectiva sociodemográfica, bien podemos definir la transición de la juventud a la edad adulta como el período que media entre el final de la etapa educativo-formativa y la asunción por parte de los jóvenes de responsabilidades de tipo familiar, principalmente, a través de la maternidad o la paternidad. Sin embargo, desde una perspectiva más bien politológica -que es la que aquí adoptamos- la juventud puede ser alternativamente conceptualizada como una etapa de transición a lo largo de la cual las personas progresivamente adquieren los recursos materiales que les facilitan el acceso a la plena ciudadanía. Estos derechos son ya formalmente reconocidos a partir de la mayoría de edad legal en todos los países, pero no siempre conllevan la capacidad efectiva de ejercicio ${ }^{3}$. Puesto que es precisamente esta capacidad la que habilita a los jóvenes para desarrollar trayectorias vitales desde autonomía, aparece como un aspecto clave del proceso al que comúnmente nos referimos como emancipación. Entendemos pues aquí como "jóvenes adultos en transición" -o jóvenes no emancipados- al grupo de jóvenes que, pese a haber adquirido ya la mayoría de edad legal-desigualmente establecida en Europa alrededor de los 18 años- se ven sin embargo sometidos a una discrepancia, en principio transitoria, entre el reconocimiento -formal, legal y constitucional- de determinados derechos y la capacidad material para su ejercicio efectivo. Desde el punto de vista legal y constitucional, pues, ya son adultos; desde el punto de vista del acceso a la ciudadanía social son todavía, sin embargo, jóvenes en transición (Patón Casas, 2003). A este respecto, Chambaz (2001) plantea cómo, pese a que la juventud viene siempre formalmente definida a partir de límites de carácter legal, cabe tener preferentemente en cuenta otros límites a los que cabe referirse como "sociales", que son precisamente los que sirven de fundamento a la idea de "jóvenes adultos". Por su parte, Golsch (2002) interpreta la transición a la vida adulta, no como una franja de edad fijada por el acceso formal a los derechos de ciudadanía, sino como un proceso en el que los individuos asumen responsabilidades en diversos ámbitos de la vida y, por ende, se incorporan progresivamente a las actividades adultas.

Sin poner en duda -al menos por el momento- que la transición de la escuela hacia el mundo del trabajo sea probablemente la de mayor importancia relativa, diversos autores han apuntado hacia tres dimensiones diferentes que, conjuntamente, configuran la transición de los jóvenes hacia la madurez y la plena ciudadanía social. Estos son: (a) la independencia del hogar

\footnotetext{
${ }^{3}$ Es cierto, sin embargo que allí donde el sistema de bienestar está muy desarrollado, el reconocimiento formal de los derechos contempla casi siempre su exigibilidad y, por tanto, la capacidad de ejercicio efectivo queda en todo caso garantizada. Helena Laaksonen, parte del estudio de los sistemas normativos en Alemania, Finlandia y Suecia, para tratar de identificar la medida y la manera en que la legislación y las regulaciones estatales inciden —particularmente en cuanto se refiere a los criterios de accesibilidad a las diversas prestaciones del estado de bienestar- en la edad de emancipación en estos tres países. Y concluye que el sistema normativo -en concreto, la edad a la que los jóvenes tienen acceso a las prestaciones sociales- es particularmente explicativo de las diferencias observables entre Finlandia y Suecia (Laaksonen, 2000).
} 
familiar de origen (household transition); (b) la entrada en el mercado laboral (school-to-work transition); y (c) la constitución de un hogar familiar propio (family transition). La heterogeneidad entre países en lo que se refiere a las transiciones juveniles y las edades de emancipación -así como la variabilidad entre individuos- viene dada por la particular combinación entre determinados acontecimientos clave que tienen principalmente lugar en el ámbito de las tres dimensiones transicionales anteriores. En concreto, es en algún momento entre los 15 y los 30/35 años que los jóvenes finalizan la etapa formativa, se incorporan al mercado laboral, se independizan del hogar familiar de origen y constituyen una familia. (Laaksonen, 2000). La evidente interrelación de las necesidades que se expresan en estos ámbitos hace ineludible el tratamiento transversal e integral de las transiciones juveniles. Pero conduce también a centrar nuestra atención en la relevancia que representa la diversidad de los sistemas de bienestar para entender la heterogeneidad europea en lo que se respecta a las oportunidades de emancipación juvenil.

Las políticas públicas, en particular las sociales, juegan un papel en extremo relevante cuando hablamos de emancipación, puesto que contribuyen a ampliar el marco de oportunidades al alcance de los jóvenes con mayor celeridad que el sistema institucional o la evolución del esquema de bienestar tomado en su conjunto (Billari, 2004). Tal y como muestra la Tabla 2, los acontecimientos que son clave en las trayectorias vitales de los jóvenes adultos no emancipados tienen una correspondencia directa con diferentes sectores de las políticas públicas y sociales: la políticas educativas y de formación, las políticas laborales, las políticas de vivienda y las políticas de apoyo a la familia. Es pues el conjunto de las políticas públicas -y sobre todo, el grado de coordinación de todas ellas en el contexto del sistema de bienestaraquello que en mayor medida determina hoy en día la diversidad entre países europeos en cuanto a la duración de la etapa de transición. Son estas políticas las que definen el marco de oportunidades y establecen, por lo tanto, las precondiciones de orden objetivo para el momento en el que los jóvenes podrán superar dicha etapa en cada una de sus diferentes dimensiones y acceder a la completa emancipación (Patón Casas, 2003). Dicho de otra manera y siguiendo a Blok et al. (1997): La acumulación de barreras y obstáculos a la emancipación juvenil hace necesaria, no sólo una atención a las necesidades específicas de los jóvenes en cada uno de los sectores de política pública -por ejemplo, las políticas de vivienda- sino también una plena coordinación de los esfuerzos entre todas aquellas áreas que tienen relevancia estratégica desde el punto de vista de las necesidades transicionales de los jóvenes. 
Tabla 2. Dimensiones transicionales i políticas públicas y socials

\begin{tabular}{|c|c|c|}
\hline Dimensiones transicionales & $\begin{array}{l}\text { Acontecimientos vitales } \\
\text { clave }\end{array}$ & $\begin{array}{l}\text { Políticas públicas y } \\
\text { sociales }\end{array}$ \\
\hline \multirow{2}{*}{ School-to-work transition } & $\begin{array}{l}\text { Finalización de la etapa } \\
\text { formativa }\end{array}$ & Políticas educativas \\
\hline & $\begin{array}{l}\text { Incorporación al mercado } \\
\text { laboral }\end{array}$ & Políticas laborales \\
\hline \multirow{3}{*}{ Household Transition } & \multirow{3}{*}{$\begin{array}{l}\text { Independización del hogar } \\
\text { familiar de origen } \\
\text { (independización } \\
\text { residencial) }\end{array}$} & Políticas de vivienda \\
\hline & & Políticas laborales \\
\hline & & $\begin{array}{l}\text { Políticas educativas } \\
\text { (becas) }\end{array}$ \\
\hline \multirow[b]{2}{*}{ Family transition } & \multirow{2}{*}{$\begin{array}{l}\text { Constitución de un hogar } \\
\text { familiar propio e } \\
\text { independiente. }\end{array}$} & Políticas de vivienda \\
\hline & & $\begin{array}{l}\text { Políticas de apoyo a } \\
\text { la familia }\end{array}$ \\
\hline
\end{tabular}

Fuente: Reelaboración propia a partir de Patón Casas (2003)

Tal y como refleja la Tabla 2, la interrelación de las condiciones que posibilitan el avance en las transiciones juveniles se expresa de forma muy clara en cuanto a las oportunidades de independización del hogar familiar de origen (household transition). Estas oportunidades vienen dadas por las condiciones de inserción laboral de los jóvenes, por las condiciones en que se dan las trayectorias educativo-formativas y, por supuesto, también por las condiciones en que se accede a la vivienda. Es la combinación de la situación de los jóvenes en cada uno de estos tres ámbitos lo que determina la gran variabilidad existente hoy en Europa en cuanto al momento en que éstos tienden a abandonar el hogar familiar de origen y acceder a la independencia residencial. En consecuencia, tanto las políticas laborales como las educativas -principalmente mediante la oferta de alojamiento en residencias, pero también los sistemas de becas y los salarios indirectos a través de la prestación de servicios a los estudiantes- inciden fuertemente en la determinación del momento en que se produce la independización respecto del hogar familiar de origen y la rapidez con que los jóvenes acceden a una completa emancipación. Y en algunos países, estas políticas pueden llegar ser incluso más determinantes que las políticas de vivienda propiamente dichas.

\subsection{Independización residencial y políticas educativas: alojamiento para estudiantes}

En el ámbito de las políticas educativas, nos parece clave el ejemplo de las residencias estudiantiles como forma particular de apoyo público a la emancipación juvenil sin perder de vista las expectativas de los propios jóvenes. Pese a no formar estrictamente parte de las políticas de vivienda, la provisión de servicios de alojamiento temporal mediante plazas en las residencias estudiantiles constituye una respuesta pública que presta apoyo a la decisión juvenil autoafirmativa, cada día más común en la mayoría de países europeos, de alargar el período formativo -incluyendo la posibilidad de dedicación a tiempo completo- sin por ello renunciar a la independencia residencial respecto del hogar familiar de origen. A este respecto 
Chambaz (2001) llama la atención sobre el hecho de que las fuentes estadísticas -y en particular las encuestas- tienden a excluir del concepto "vivienda" las diversas formas de alojamiento colectivo -las residencias de estudiantes, pero también los foyers de estudiantes 0 de jóvenes trabajadores- centrando su atención exclusivamente en las viviendas llamadas "ordinarias".

En lo que se refiere a las residencias estudiantiles, si bien es cierto se trata de una solución provisional desde el punto de vista de la idea de emancipación -pues se trata de una solución de carácter coyuntural en respuesta a las necesidades juveniles de independización residencial temporal- contribuye de hecho a garantizar márgenes muy amplios de autonomía para los estudiantes a lo largo de su proceso de transición a la vida adulta. Esto es así en determinados países -los nórdicos como paradigma, pero también Francia y Holanda- donde las prestaciones para estudiantes tienden a incluir toda la etapa formativa secundaria y también la postsecundaria. Y no es así, en cambio, en países como España donde, ante la ausencia de prestaciones públicas de apoyo susceptibles de compensar el retraso en el acceso al trabajo como fuente de ingresos -retraso que se da como consecuencia del alargamiento en el período formativo a tiempo completo- los jóvenes estudiantes ven reducidas sus oportunidades para el abandono del hogar familiar de origen (Jurado Guerrero, 2003; CES, 2002).

Es bien cierto que estas prestaciones se vinculan a la condición de estudiantes. A este respecto cabe argumentar, en primer lugar -siguiendo a Corijin (1999) y adoptando de nuevo una perspectiva sociodemográfica- que la transición a la edad adulta de define como el período que media entre el final de la etapa educativo-formativa y la asunción por parte de los jóvenes de responsabilidades de tipo familiar. Así, en primer lugar, la permanencia en las instituciones educativo-formativas es considerada como una de las características esencialmente definitorias del concepto de juventud como etapa en la vida de las personas. En segundo lugar, siguiendo a Chambaz (2001) hay que tener en cuenta que la emancipación temprana es precisamente más frecuente en aquellos países en los que las formas de vivienda colectiva están más desarrolladas. En Holanda, por ejemplo, los jóvenes que se emancipan sin pareja -y esta es, de hecho, la forma hoy en día más común y creciente en este país- tienden a hacerlo en alojamientos compartidos o residencias de estudiantes, más que en vivienda independiente de alquiler o de compra; esto es así aún cuando la mejora de las oportunidades de acceso a la vivienda ha conducido a un aumento del peso relativo de las diversas formas de independización en solitario, a excepción de la opción por alternativa de la compra (Mulder, 2000). En tercer lugar, es precisamente en los países en los que los jóvenes estudiantes tienden a emanciparse mediante residencias estudiantiles donde generalmente éstos pueden disponer simultáneamente de políticas de vivienda social avanzadas, lo que les permite seguir manteniendo la independencia del hogar familiar de origen una vez finalizado su período formativo y habiendo gozado ya hasta entonces del margen de autonomía que proporcionan la independencia residencial provisional (Jurado Guerrero, 2003). Finalmente, no cabe duda de que -pese a su provisionalidad- estas políticas contribuyen a garantizar la maduración y la afirmación de los jóvenes estudiantes como personas independientes; o, si se quiere expresar desde un punto de vista más adultocrático, promueven el acceso progresivo a las responsabilidades representadas por la vida adulta (Patón Casas, 2003).

Jurado Guerrero (2003) ha estudiado el caso particular de Francia donde -a diferencia de España- es frecuente que los jóvenes abandonen el hogar familiar de origen durante la etapa formativa. Así, un alto porcentaje de los jóvenes franceses tienen como primera residencia independiente una habitación en una residencia universitaria. Cabe tener en cuenta en primer 
lugar -tal y como Jurado Guerrero destaca- el hecho que las residencias universitarias están más extendidas y son mucho más accesibles en Francia que en España. En segundo lugar, es necesario referirse también a la importancia relativa las becas-salario, las cuales presentan un mayor grado de cobertura entre los jóvenes franceses que entre los jóvenes los españoles. $Y$ en tercer lugar, no debemos olvidar que los estudiantes franceses -a diferencia de los españoles- tienen acceso a dos tipos diferentes de ayudas al alquiler, las cuales se presentan como alternativas adicionales a la de la residencia estudiantil. Nótese que, en este caso, es la combinación de las políticas de vivienda con otras políticas sociales -en este caso, las políticas educativas- lo que facilita y promueve la independización temprana de los estudiantes franceses y, por lo tanto, la apertura del camino hacia la completa emancipación.

\subsection{Independización residencial y políticas de mercado laboral: ingresos salariales y estabilidad en el empleo}

\subsubsection{Ingresos salariales, sistema de bienestar y oportunidades de acceso a la vivienda}

En lo que se refiere a las políticas laborales, parece a primera vista muy clara la relación que cabe establecer entre las oportunidades de emancipación y la independencia residencial, por un lado, y la accesibilidad de la vivienda y los ingresos salariales de los jóvenes por otro. Chambaz (2001) llama la atención sobre el hecho de que la medición de los recursos a disposición de los jóvenes constituye un ejercicio en extremo complicado dado que -en muchos casos y al menos en parte- los ingresos proceden de transferencias familiares. Así, por ejemplo, los jóvenes pueden haber conseguido la independencia residencial y, sin embargo, ser todavía dependientes desde el punto de vista financiero. Estos jóvenes -como es el caso de muchos estudiantes en países como Francia- pueden estar recibiendo transferencias familiares para el pago del alquiler $u$ otros gastos vinculados al mantenimiento de un hogar independiente. Por otro lado, jóvenes trabajadores -incluso con un trabajo estable y un salario estándar- pueden haber tomado la decisión -autónoma y voluntaria- de permanecer más tiempo en el hogar familiar de origen. El hecho es que estos jóvenes trabajadores podrán disponer de un grado más o menos alto del libertad en el seno de la familia, al margen de la autonomía económica que, de por si, ya les proporciona el trabajo. Pero no habrán accedido en todo caso todavía -en algunos casos seguramente por voluntad propia- a la autonomía que comporta la asunción plena de determinadas responsabilidades adultas, entre las cuales cabe situar la decisión de vivir independientemente y la de constituir un hogar distinto del hogar familiar de origen (Chambaz, 2001; Patón Casas, 2003).

El análisis transnacional muestra, de hecho, una relación muy desigual y ambigua entre los ingresos salariales de los jóvenes y la independencia de éstos respecto del hogar familiar de origen. A este respecto, Billari (2004) ha estudiado cómo el impacto de los ingresos sobre las oportunidades de emancipación juvenil parece ser diferente en función del sistema de bienestar. El nivel de ingresos salariales es un factor relevante precisamente en aquellos países en los que el abandono del hogar familiar de origen se produce más tarde. Esto es claramente así en los países del área mediterránea, dotados de un estado social débil y un régimen de bienestar apoyado sobre todo en la familia. Tal y como cabría sin duda esperar, el nivel de ingresos es también un factor impulsor de la emancipación en los regímenes de bienestar de tipo liberal, en los que la satisfacción de las necesidades sociales se apoya principalmente en el mercado (Reino Unido, Irlanda). En cambio, en cuanto se refiere a los países nórdicos -principalmente, pero no tan solo- las transferencias públicas y los salarios indirectos en forma de servicios reducen la importancia relativa de los ingresos procedentes del 
mercado laboral. Se trata en este caso, además, de países en los que las políticas de vivienda están tan desarrolladas en su vertiente social, que en gran medida cubren las necesidades transicionales de los jóvenes con bastante independencia respecto de los niveles de ingreso salarial. Es por ello que las políticas que impliquen una mejora salarial en los países del área mediterránea contribuirán probablemente a avanzar la edad de emancipación en mayor medida que, por ejemplo, en los países nórdicos (Billari, 2004).

En cuanto se refiere a los países del área mediterránea, Aaasve et al. (2000) han estudiado el impacto de la situación laboral de los jóvenes -y en particular, de sus ingresos- sobre el abandono del hogar familiar de origen en el caso particular de Italia. A este respecto, se contemplan dos efectos posibles. Por un lado, el efecto de la autosuficiencia financiera (selfreliance effect); $y$, por otro, el del atractivo de los ingresos a la hora de formar pareja (goodcatch effect). Vale decir que se detectan diferencias muy relevantes en el comportamiento por géneros. Así, el empleo y los ingresos salariales constituyen un factor relevante para la emancipación de los hombres jóvenes, mientras que sólo lo es entre las mujeres de muy altos ingresos. Si seguimos a Moreno Minguez (2005) advertiremos que -al menos en lo que respecta a los países mediterráneos del sur de Europa- las diferencias de género en cuanto al impacto del empleo y los ingresos sobre la emancipación de los y las jóvenes está relacionado con la persistencia de estructuras de organización familiar tradicionales basadas en el modelo del varón sustentador (male breadwinner). Este modelo está extendido precisamente en aquellos países en los que el sistema de bienestar contempla una intervención pública limitada, tanto en lo que se refiere a las políticas de mercado laboral como en lo que respecta a las políticas de apoyo a la familia.

En cuanto a los países con régimen de bienestar de tipo liberal -apoyados sobretodo en el mercado- Ermisch (1997) ha estudiado -mediante un preciso modelo econométrico aplicado al caso particular del Reino Unido- la relación que se establece entre la decisión de abandonar el hogar familiar de origen y el nivel de ingresos salariales de los jóvenes. El estudio concluye que los jóvenes con ingresos más altos tienden en mayor medida a iniciar el proceso de emancipación; y son, adicionalmente, menos propensos a experimentar un retorno hacia el hogar familiar de origen. El análisis de la relación entre los ingresos de los jóvenes y la accesibilidad de la vivienda apunta a que los precios del mercado inmobiliario son también -en combinación con los niveles salariales, tal y como cabría esperar- un factor importante en la promoción o la inhibición de la independencia residencial y en la formación de nuevos hogares en el Reino Unido.

Cabe hacer referencia específica, finalmente, al caso español. En España, la combinación entre la ausencia práctica de vivienda social y la escasa oferta de vivienda de alquiler -por un lado- y los altos precios del mercado inmobiliario -por otro- hacen de los salarios un factor clave en cuanto a las oportunidades de emancipación. En España, comportamientos juveniles tales como la emancipación en pareja y con dos salarios no constituyen sólo una "preferencia" -tal y como se pretende en ocasiones- sino también una necesidad. Si atendemos a Jurado Guerrero (2003), advertiremos que se trata -como en el caso de la emancipación juvenil tardía y la permanencia en el hogar familiar de origen durante la etapa formativa- de conductas económicamente racionales, dados unos determinados incentivos mercantiles y públicos. No obstante, la centralidad del nivel salarial como factor responsable del retraso en la emancipación de los jóvenes españoles se ve desplazada -tal y como veremos enseguida y sobretodo en relación con las características de la oferta del mercado inmobiliario- por un 
condicionante de mucha mayor importancia, como es la precariedad laboral y la gran inestabilidad del empleo (CES, 2002).

\subsubsection{Flexibilidad laboral, estabilidad en el empleo y acceso a la vivienda}

Si bien es cierto que las políticas de vivienda juegan un papel complementario en la protección frente a los riesgos sociales, particularmente en aquellos países en los que la vivienda en propiedad está muy extendida. Avramov (2006) destaca la importancia fundamental de la inserción en el mercado laboral convencional -junto con las políticas de bienestar tendencialmente desmercantilizadoras- para la integración social de los individuos y de las familias. $Y$ esta importancia fundamental puede predicarse tanto en lo que se refiere al acceso -esto es, la inserción laboral propiamente dicha- como en lo que se refiere a los niveles salariales $y$, sobre todo, la estabilidad del empleo.

Refiriéndose específicamente a los jóvenes, Golsch (2002) ha estudiado el impacto que en España ha tenido el aumento de la flexibilidad laboral sobre el proceso de transición a la vida adulta. Golsch afirma que -al menos en lo que se refiere a España- una posición laboral estable aparece claramente como prerrequisito para la emancipación juvenil. De hecho -dada la situación del mercado inmobiliario- los jóvenes españoles tienden a permanecer en el hogar familiar de origen hasta el momento en que consiguen establecer una base económica sólida que les permita la asunción de compromisos a largo plazo.

Aun siendo la estabilidad laboral de importancia capital para los procesos de emancipación juvenil -sobre todo allí donde la vivienda en propiedad es la norma y las políticas sociales están menos desarrolladas, esto es, en los países del área mediterránea- corresponde sin embargo a nuestro artículo, destacar el papel específico de las políticas de vivienda sobre las oportunidades de de los jóvenes para emanciparse, estableciendo su peso relativo frente a las oportunidades que también se ofrecen desde las políticas de mercado laboral. A este respecto en primer lugar, Avramov (2006) plantea la necesidad de hacer corresponder la flexibilización de los mercados laborales con políticas de vivienda susceptibles de permitir a la población ajustarse a estos cambios, promoviendo la una oferta de alquiler suficiente $-y$ en condiciones de fácil accesibilidad- precisamente allí donde el crecimiento económico genera demanda de mano de obra más flexible. En segundo lugar, Flaquer (2004) nos advierte que, en cuanto se refiere a los países del sur de Europa, "las dificultades de los jóvenes para emanciparse de sus hogares de origen debe relacionarse no sólo con la precariedad del empleo, sino también con la práctica ausencia de programas de vivienda social de alquiler y con la insuficiencia del mercado privado de alquiler".

\section{El papel específico y el peso relativo de las políticas de vivienda en las oportunidades de emancipación juvenil}

Tal y como hemos venido argumentando -y siguiendo ahora a Avramov (2006)- cabe tener en cuenta el hecho de que los sistemas de bienestar definen el marco en el que se produce la redistribución de los recursos, y esto tanto en lo que respecta a los recursos materiales como en lo que se refiere los no materiales. En relación con ello, hasta ahora hemos visto cómo los factores institucionales y los sistemas de bienestar definen la estructura básica sobre la que se dan las oportunidades de emancipación, así como los límites entre los cuales pueden desarrollarse las expectativas juveniles de independencia respecto del hogar familiar de origen. Hemos argumentado también cómo -debido a la interconexión de las necesidades 
transicionales de los jóvenes en diversos ámbitos- la emancipación juvenil requiere de un tratamiento integral en el que se tenga en cuenta la interrelación de los diferentes factores que la condicionan. $Y$ nos hemos referido, seguidamente, a las áreas de las políticas públicas y sociales que, coordinadas, pueden contribuir a facilitar las transiciones juveniles y promover el acceso de los jóvenes a la plena ciudadanía. Nos queda, finalmente-en coherencia con el principal objetivo de este artículo- abordar el peso específico de las políticas de vivienda sobre las oportunidades de independización residencial y sobre el proceso de emancipación de los jóvenes.

\subsection{El impacto de los regímenes de propiedad de la vivienda sobre las oportunidades de emancipación juvenil e independización residencial a partir de Mulder y Billari}

Mulder y Billari (2006) han estudiado la relación entre los diversos regimenes de propiedad de la vivienda y las tasas de fertilidad en diferentes países europeos, clasificándolos en cuatro regímenes de propiedad en función de la relación que se establece entre la extensión de la propiedad como forma de tenencia, la función social que ésta cumple y las dificultades relativas en el acceso a los créditos hipotecarios.

Así, en los países del sur de Europa -Italia, España y Grecia- el acceso a la vivienda se ve en extremo dificultado por la particular combinación de la extensión de la propiedad como forma de tenencia y el limitado acceso a las hipotecas como forma de financiación de los inmuebles. Y esta situación en relación con la vivienda, junto con el retraso en la emancipación y las bajas tasas de fertilidad, cabe interpretarla como parte del sistema de bienestar que es característico de estos países. En lo que respecta a este mismo grupo de países Hoekstra (2006) ha analizado la paradoja subyacente en el régimen de propiedad mediterráneo, esto es, la coexistencia de precios elevados junto con un alto porcentaje de viviendas desocupadas. Hoekstra apunta, entre los factores clave de esta paradoja, hacia la percepción social de la vivienda como inversión rentable y segura. Así, en estos países, la opción por la tenencia en propiedad está más relacionado con el tipo de sistema de bienestar que los caracteriza que con pretendidas preferencias y predisposiciones culturales arraigadas. A este respecto, Flaquer (2004) ha reflexionado sobre la significación de la compra de vivienda en las sociedades mediterráneas, en las que se interpreta como "una suerte de autoprotección familiar", como una "inversión contra los riesgos sociales" y como "un recurso muy importante en países en que la red de seguridad es muy deficiente y en que las prestaciones familiares son escasas".

En el otro extremo se encuentran los países en los que para muchos jóvenes la propiedad de la vivienda no es la primera forma de acceso a la independencia residencial, sino que se interpreta como la fase de tenencia correspondiente a un ulterior avance en la trayectoria vital de las personas. Se trata de una forma de tenencia que se identifica con la situación de aquellas familias que, en algún momento de su vida, alcanzan un nivel ingresos suficiente y a la vez estable. Mulder y Billari (2006) incluyen aquí a los países nórdicos, a excepción de Noruega, donde la propiedad está muy extendida y es fácilmente accesible. Pero también comparten este régimen de propiedad países como Alemania, Holanda, Suiza, Luxemburgo y el Reino Unido. Esta clasificación es consistente con el estudio que -a partir de fuentes de tipo cualitativo- Toussaint y Elsinga (2006) han llevado a cabo en relación con la significación que las diversas alternativas de tenencia presentan para las personas en diferentes países europeos. Así, tanto en Alemania como en Suecia y Holanda el sector del alquiler es percibido como una buena alternativa a la propiedad, muy en particular para las personas jóvenes en proceso de emancipación. En Finlandia y el Reino Unido el alquiler también es percibido como 
una opción socialmente aceptable para los hogares jóvenes, si bien en este caso se concibe como una solución de carácter temporal y poco segura en el largo plazo, sobre todo en lo que respecta al sector de alquiler privado.

Entre uno y otro extremo se encuentran, por un lado, los países en los que la propiedad está muy extendida pero en los que el acceso a esta forma de tenencia se ve facilitado por un acceso generalizado a las hipotecas -donde encontramos a Irlanda, Islandia y Noruega. Y, por otro lado, los países en los que el alquiler se concibe como una alternativa a la propiedad, la cual es percibida como reservada en exclusiva a las personas y a las familias que pueden permitírselo. En este último grupo, Mulder y Billari (2006) sitúan a Austria, Bélgica, Francia y Portugal. Esta clasificación es también consistente con los resultados referidos más arriba, obtenidos por Toussaint y Elsinga (2006), a partir de su estudio sobre la significación social de la vivienda en Europa. Así, tanto en Bélgica como en Portugal -donde la emancipación juvenil es relativamente tardía: véase Tabla 1- el sector de alquiler adopta connotaciones negativas vinculadas a la percepción de la tenencia como insegura, lo que sin duda cabe relacionar con la baja presencia relativa del alquiler social (véase Tabla 3). Así, en estos dos países el alquiler es concebido como una alternativa para las personas que se encuentran en situación de desventaja relativa, esto es, las que no disponen de los recursos suficientes para optar a la propiedad como la forma de tenencia más segura.

Si relacionamos esta categorización con las edades de emancipación de los jóvenes -véase Tabla 1- observaremos una fuerte correlación entre la edad de independización residencial de los jóvenes, el régimen de propiedad característico y el tipo de sistema de bienestar con el que los países del sur de Europa responden a las necesidades de las personas. A este respecto, Martins y Villanueva (2006) han estudiado recientemente, para el caso de Portugal-situado por Mulder y Billari (2006) en un régimen de propiedad distinto del que hacen corresponder con resto de países mediterráneos- el impacto que el acceso limitado a las hipotecas tiene sobre las oportunidades de independización residencial de los jóvenes. Estos autores concluyen que acceder a un crédito hipotecario puede tener un impacto de entre 31 y 54 puntos porcentuales sobre las diferencias en las edades de independización residencial; y que el uso diferencial del crédito en los diferentes países de Europa puede llegar a explicar entre un 16 y un $20 \%$ de la distancia entre el norte y el sur en cuanto a las edades de abandono del hogar familiar de origen.

Sin embargo, si bien el sistema de bienestar se correlaciona de forma muy clara con los diferentes regímenes de propiedad y con las oportunidades de emancipación juvenil en lo que respecta al área mediterránea, la situación no es tan clara en lo que se refiere al resto de países y sistemas de bienestar. Intentaremos argumentar el porqué en el apartado siguiente, destacando el papel específico de la extensión del alquiler social como alternativa de tenencia.

\subsection{La relevancia de las políticas de vivienda a la luz de la importancia relativa de la extensión del alquiler social}

Si bien siguiendo a Mulder y Billari (2006) los países nórdicos -a excepción de Noruegacomparten con Alemania, Holanda, Suiza, Luxemburgo y el Reino Unido un mismo régimen de propiedad, estos países presentan una gran heterogeneidad en cuanto al sistema de bienestar dominante. La característica común para este conjunto de países -en los que el alquiler es percibido por los jóvenes y sus familias como una opción de tenencia accesible y ajustada a las necesidades transicionales- es una emancipación rápida y temprana (en menor medida, sin 
embargo, en cuanto se refiere a Alemania y el Reino Unido). Esta circunstancia nos permite situar las políticas de vivienda social -con relativa independencia respecto del sistema de bienestar considerado globalmente- en un lugar de centralidad como marco explicativo de las correlaciones y discrepancias observadas para este conjunto de países.

Tabla 3. Regímenes de tenencia de la vivienda en diversos países de Europa

\begin{tabular}{|l|c|c|c|}
\hline \multirow{2}{*}{ HOLANDA } & \multicolumn{2}{|c|}{ Tenencia vivienda (en porcentaje) * } \\
\cline { 2 - 4 } & Alquiler Social (\%) & Alquiler Privado (\%) & Propiedad (\%) \\
\hline ALEMANIA & 35 & 17 & 48 \\
\hline AUSTRIA & 26 & 36 & 55 \\
\hline SUECIA & 23 & 22 & 62 \\
\hline REINO UNIDO & 22 & 16 & 69 \\
\hline DINAMARCA & 21 & 10 & 55 \\
\hline NORUEGA & 19 & 26 & 60 \\
\hline FRANCIA & 18 & 22 & 54 \\
\hline FINLANDIA & 17 & 21 & 67 \\
\hline IRLANDA & 14 & 19 & 80 \\
\hline ALEMANIA OCC. & 11 & 9 & 43 \\
\hline BÉLGICA & 10 & 47 & 63 \\
\hline ITALIA & 7 & 30 & 78 \\
\hline PORTUGAL & 6 & 16 & 68 \\
\hline SUIZA & 4 & 28 & 31 \\
\hline LUXEMBURGO & 3 & 66 & 67 \\
\hline ESPAÑA & 2 & 31 & $\mathbf{8 6}$ \\
\hline GRECIA & 2 & 12 & $\mathbf{7 4}$ \\
\hline
\end{tabular}

Fuente: Trilla (2001). Extracto. Cfr. Tabla 1

Así, en todos los países nórdicos -incluida en este caso Noruega- el alquiler social es una forma de tenencia muy difundida, situándose bastante por encima de la media europea. Pero, tal y como se muestra en la Tabla 3, el alquiler social presenta también una gran difusión en Holanda (35\%), en Alemania (26\%) y en el Reino Unido (21\%). Por lo que respecta a Suiza y Luxemburgo, donde la vivienda social es prácticamente inexistente (3 y $2 \%$ respectivamente) y donde la emancipación juvenil es sin embargo relativamente rápida y temprana- la explicación seguramente remite al dinamismo de sus respectivos mercados inmobiliarios. $Y$ para el caso particular de Suiza, cabe referirse adicionalmente a la amplísima disponibilidad de la oferta en alquiler, un forma de tenencia que, según veremos, es muy adecuada para favorecer la independencia residencial de los jóvenes.

La emancipación juvenil es también rápida y temprana en Francia y Austria, países que comparten sistema de bienestar y, a su vez, un mismo régimen de propiedad en el que el alquiler aparece como una alternativa aceptable de tenencia para los jóvenes. Los casos de Bélgica y Portugal, que comparten régimen de propiedad con Francia y Austria -y sin embargo presentan transiciones juveniles retardadas- contribuyen a mostrarnos, de nuevo, la importancia relativa del alquiler social como alternativa para la emancipación juvenil. Así, mientras que en Bélgica y Portugal el alquiler social está muy por debajo de la media europea (7 y 4\%), en Austria se sitúa claramente por encima (23\%) y en Francia aparece alrededor de la media correspondiente a la Unión Europea (17\%). En relación al caso de Francia ya hemos hecho referencia más arriba al impacto que sobre la emancipación juvenil más temprana tiene la presencia de alternativas de alojamiento compartido (foyers) y las residencias estudiantiles. 
Finalmente, cabe referirse a los países del área mediterránea, donde el sistema de bienestar se corresponde con un determinado régimen de propiedad -esto es, el de "difícil acceso", siguiendo a Mulder y Billari (2006) - y a la vez con una emancipación juvenil muy tardía. En estos países, la presencia del alquiler social es mínima (España, 2\%; Portugal, 4\%; Italia, 6\%) o, como ocurre en el caso particular de Grecia, virtualmente inexistente. A esta situación cabe añadir la también escasísima presencia del alquiler privado en los casos particulares de Italia (16\%) y sobretodo España (12\%), viniendo a reforzar el marco explicativo con el pretendemos justificar el retardo en la emancipación residencial de los jóvenes. Así, estos dos países, donde la extensión del régimen de propiedad ahogado las formas de tenencia alternativas -alquiler social o privado- presentan a su vez una emancipación juvenil considerablemente más tardía que Portugal y Grecia donde, pese a todo, los jóvenes pueden disponer del recurso al alquiler bajo régimen privado (28 y $26 \%$, respectivamente).

\section{Las políticas de transición afirmativa: régimen de tenencia y tipología de la vivienda}

Las políticas afirmativas de juventud son a menudo identificadas con aquellas intervenciones de la administración en las que se contempla la juventud como un recurso y en las que se aborda el período juvenil como una etapa plena de la vida, que ha de ser potenciada e impulsada, ayudando a los jóvenes "a ser jóvenes". Las políticas de transición -en cambio y en contraposición las afirmativas- pretendidamente abordan la juventud desde su comprensión como período problemático de la vida, que ha de ser minimizado mediante la provisión de recursos -como por ejemplo el acceso a la vivienda- susceptibles de prestarles apoyo en su proceso de transición hacia la vida adulta, esto es, ayudándolos a "dejar de ser jóvenes". En otro lugar (Patón Casas, 2003) hemos defendido la propuesta de las políticas de transición afirmativa, pretendiendo señalar la posibilidad $-\mathrm{y}$ la conveniencia- de responder a las necesidades nucleares de los jóvenes -a sus necesidades transicionales- no para convertirlos rápidamente en "adultos" -puesto que en muchos casos, de hecho ya lo son- sino para que puedan expresar sin impedimentos de carácter objetivo sus propias aspiraciones autoafirmativas. Es éste un concepto muy próximo al de políticas de emancipación, siempre y cuando sea interpretado en su sentido más amplio, vinculado a los derechos de ciudadanía y, por lo tanto, no sólo referido al proceso de independización residencial.

Cuando abordamos las políticas de vivienda desde esta perspectiva -y en relación con las necesidades de los jóvenes a lo largo de su proceso de emancipación- surgen tres cuestiones clave que es necesario tener en cuenta para no perder de vista la relación mutua entre, por un lado, el marco de oportunidades; $y$, por otro, las condiciones materiales de las que surgen -y a partir de las cuales se desarrollan- las expectativas juveniles en cuanto a las diversas alternativas de independencia residencial y formas de vida y convivencia. Estas cuestiones clave se refieren a las alternativas de tenencia que se hace accesibles a los jóvenes accesible, a la tipología de inmuebles que se pone a su disposición y a la franja de edades a la que dirigir, en su caso, las políticas de vivienda específicamente "juveniles". En este apartado abordaremos las dos primeras cuestiones y en el siguiente aportaremos algunos argumentos en relación con la tercera.

\subsection{Las tendencias sociodemográficas, las necesidades juveniles transicionales y diversificación de la tipología de los inmuebles}

Si parece evidente y de toda lógica afirmar que las tendencias demográficas $-y$ las necesidades derivadas- tienen un impacto sobre la demanda social de vivienda, Mulder (2006) 
advierte que la relación entre la vivienda y la población es compleja y que se produce a dos bandas. Así, tal y como refiere también Avramov (2006), la pluralización de la oferta inmobiliaria contribuye simultáneamente a definir el marco de oportunidades al alcance de los jóvenes, no sólo en cuanto se refiere a las posibilidades de acceso a la vivienda o en cuanto tiene que ver con las decisiones relativas a la ubicación residencial, sino impactando también sobre las expectativas en cuanto a las opciones alternativas de vida, las trayectorias vitales esperadas por los jóvenes y sus familias, las formas de convivencia percibidas como posibles y los modelos de organización familiar incorporados al imaginario juvenil (Avramov, 2006, Mulder, 2006). Así, cualquier conjunto de políticas públicas -en este caso, de vivienda- que se proponga responder a lo que se ha dado en llamar "nueva condición juvenil", no sólo debe atender a los modos de vida actuales de los jóvenes -a sus necesidades efectivas y sus demandas explícitas- sino que debe tener también por objetivo la ampliación del marco real de oportunidades, dejando margen suficiente para la exploración de modos de vida alternativos no estandarizados- y para el surgimiento consiguiente de aspiraciones autoafirmativas (Patón Casas, 2003).

Los hogares unipersonales, las familias uniparentales y las relaciones sin cohabitación son fenómenos nuevos que producen y producirán cambios en la demanda inmobiliaria (Avramov, 2006). En lo que respecta a los jóvenes, las previsiones que se desprenden de las actuales tendencias sociodemográficas en Europa nos indican que la secuencia tradicional de abandono del hogar familiar de origen, para la formación de matrimonio y creación de una nueva unidad familiar dejará de ser la única trayectoria de eventos vitales en el proceso de transición de los jóvenes a la vida adulta; y en muchos países, incluso podría dejar de ser la predominante.

En algunos países, sobretodo en los del sur de Europa, las tendencias anteriormente apuntadas son todavía incipientes. Dado que la rigidez de sus mercados inmobiliarios dificulta la adaptación de la oferta de viviendas a las necesidades cambiantes, contribuye a desincentivar la pluralización del comportamiento juvenil en cuanto se refiere a la independización residencial, a la constitución de pareja y a la formación de una familia (Mulder y Billari, 2006).

Así, si se pretende ampliar el abanico de oportunidades al alcance de los jóvenes y facilitar la opción por unas u otras trayectorias transicionales alternativas, cabe defender la conveniencia de pluralizar la oferta inmobiliaria. Se trata de dar respuesta a las necesidades juveniles específicas y de proporcionar una salida a los deseos de experimentación con nuevas formas de vida y convivencia mediante la diversificación de la tipología de inmuebles que se hace accesible a los jóvenes. En este sentido, Avramov (2006) apunta hacia el hecho de que el abandono del hogar familiar se produce en cada caso por razones muy diversas. $Y$, si esto es así, entonces la vivienda ha de jugar un papel diferente en cada una de las trayectorias a que da lugar esta diversidad. Esta es la razón por la cual la respuesta a las necesidades juveniles no puede ser otra que la pluralización de los stocks inmobiliarios, particularmente en lo que se refiere a la diversidad de calidades y a las características de los inmuebles en cuanto a tamaño y equipamientos (Avramov, 2006; Mulder, 2006).

La limitación en cuanto a la tipología de vivienda ofertada, generalmente se tiende a consolidar una norma social de la estabilización residencial mediante la cual se reproducen esquemas estandarizados y pautas de comportamiento más bien tradicionales, esto es, similares a las que caracterizaron las trayectorias de vida de las generaciones inmediatamente anteriores. En general, allí donde la oferta de vivienda es uniforme -y poco diversificada en cuanto a tipología- 
se tiende a condicionar a los jóvenes hasta el punto de llegar a concebir la constitución de un hogar familiar de tipo tradicional como la única alternativa de entre las muchas formas de vida y convivencia que en habrían de ser posibles. Así, sin embargo, no es de esperar -en menor medida aún cuando la emancipación se produce a edades tempranas- que todos los jóvenes necesiten o deseen acceder a la independencia residencial mediante el recurso a viviendas de tipo estándar, entendiendo como tales los inmuebles con una distribución convencional de los espacios, cocina separada u otras características similares. Tampoco parecen proporcionar una adecuada respuesta a las necesidades que surgen de la emancipación juvenil temprana las viviendas muy amplias, mediante la oferta de las cuales se venga a dar por hecha una periodización estereotipada de las trayectorias vitales, presuponiendo que la independencia residencial de los jóvenes ha de tener siempre -o casi siempre- lugar en orden al matrimonio y la posterior formación de una familia.

A este respecto, Clapham (2006) advierte que se ha estudiado poco la relación que se cabe establecer entre las características de la oferta inmobiliaria y la significación que para las personas tiene la vivienda, así como los estilos de vida y las identidades vinculadas al uso de los inmuebles. Clapham dispone sin embargo de argumentos suficientes para sostener que, en general, la significación que las personas otorgan a la vivienda está estrechamente vinculada a la manera en que se interpretan a sí mismas; y que la manera en se hace uso de una vivienda contribuye en gran medida a la definición de los estilos y trayectorias de vida.

\subsection{Necesidades juveniles transicionales y alternativas de tenencia disponibles en el mercado inmobiliario}

Si adoptamos la perspectiva de la juventud como etapa de transición -caracterizada por la incertidumbre y la imprevisibilidad en relación con el futuro- las necesidades juveniles de vivienda -sobre todo en lo que respecta a los jóvenes que se emancipan a edades más tempranas- parecen claramente diferentes de las de aquellas otras personas que, habiendo superado la etapa transicional, han optado ya por estabilizar sus espacios de vida y convivencia. Difícilmente, pues, desearán todos los jóvenes acceder a la emancipación por la vía de la compra de una vivienda definitiva, puesto que en ese aso ésta debería ajustarse a necesidades que, en su caso, tendrán lugar en el medio y el corto plazo.

En cuanto la forma de tenencia, parece bastante claro, en consecuencia, que el alquiler -ya sea éste social o privado- se adaptará probablemente muy bien a las necesidades y las expectativas de los jóvenes en el momento de su primera independización residencial, particularmente cuando ésta se produzca a edades tempranas. Así, tanto si el alquiler es privado como si se trata de alquiler social, esta forma de tenencia no requiere de inversión previa ni determina la asunción de compromisos vitales o hipotecarios de largo plazo. Esto es particularmente importante para los jóvenes que -aunque quisieran- difícilmente podrían acceder un crédito inmobiliario. Así, tanto desde el punto de vista de la accesibilidad de la vivienda, como desde una la perspectiva que contemple el carácter transicional del estatus juvenil, la tenencia en alquiler debería poder ser una opción accesible para los jóvenes en todos los países europeos. Adicionalmente, los procesos de individualización y el surgimiento de la llamada "nueva condición juvenil" sitúan esta forma tenencia en el punto de mira de aquellos jóvenes que han optado por formas de convivencia no estandarizadas -o por vivir solos- y que prefieren no asumir -incluso pudiendo hacerlo- compromisos hipotecarios de largo plazo. 
Gráfico 1. Proporción representada por la tenencia en régimen de alquiler privado para el conjunto de la población y para los jóvenes de entre 25 y 35 años de edad en diferentes países europeos.

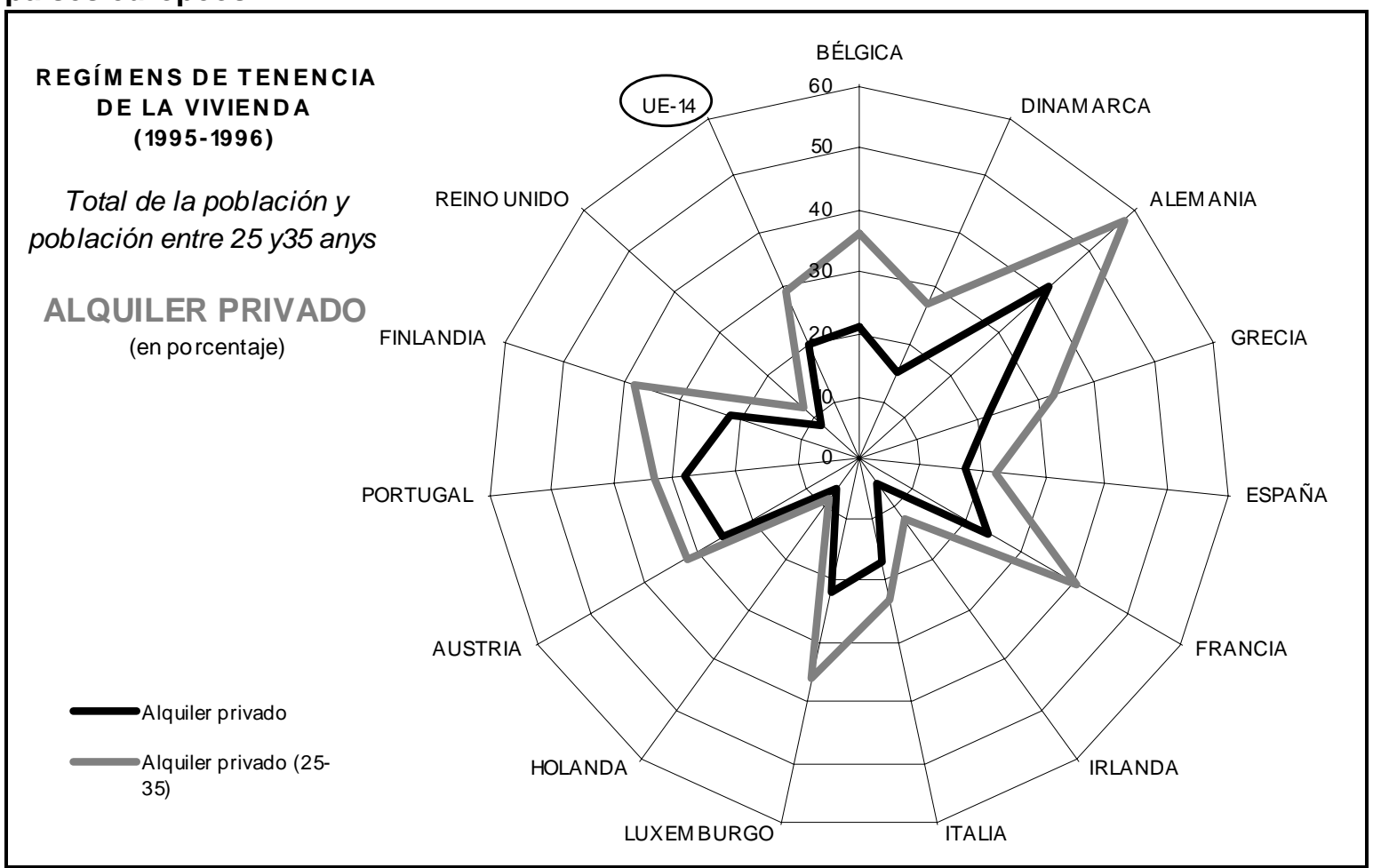

Fuente: Elaboración propia a partir de los datos del estudio Housing Conditions in Europe (Giorgi, et al): ECHP Wave 3 (1995 i 1996) y UDB Database 2/2002

El Gráfico 1 y el Gráfico 2 muestran la proporción que la tenencia en alquiler, -tanto privado como social- representa para los jóvenes entre 25 y 30 años y para el conjunto de la población en diversos países de la Unión Europea. Cada uno de estos dos gráficos es, pues, ilustrativo de la situación relativa de los jóvenes en cuanto a la forma de tenencia de sus inmuebles. Estos gráficos nos permiten establecer comparaciones transnacionales y, a su vez, examinar la relación que en cada país se establece entre la situación particular de los jóvenes y la correspondiente al conjunto de la población. Hemos optado por no incluir aquí un tercer gráfico -el de la tenencia en propiedad- por el hecho evidente de que -al ser complementario respecto de los otros en la representación de la distribución porcentual- no nos habría proporcionado ninguna información adicional.

En relación con el Gráfico1 cabe destacar el hecho de que los jóvenes de entre 25 y 30 años recurren en mayor medida al alquiler privado que las personas de otras franjas de edad en todos los países europeos considerados. Esto es así en mayor medida en aquellos países en los que este tipo de oferta existe para el conjunto de la población, mostrando de forma muy clara la predisposición de los jóvenes hacia esta forma particular de tenencia. Así, aunque en Holanda, el Reino Unido e Irlanda se observa una menor presencia del alquiler privado entre los jóvenes éstos se ven alternativamente cubiertos por la vivienda social, si bien es cierto en igual proporción que el conjunto de la población -véase el Gráfico 2.

El Gráfico 2 nos muestra cómo, en general, la vivienda social de alquiler -a excepción del caso particular de Francia, donde se ha desarrollado una oferta importante y específicamente 
dirigida a las personas jóvenes- cubre casi en igual porcentaje a las personas de entre 25 y 30 años de edad que al conjunto de la población de sus respectivos países. Así, parece claro que la oferta de vivienda social de alquiler no se tiende generalmente a focalizarse sobre los jóvenes, sino que viene a dar respuesta a las necesidades del conjunto de la población. Y, como hemos visto, a excepción de Holanda y el Reino Unido -donde el alquiler social proporciona una muy buena cobertura- los jóvenes tienden a recurrir también al mercado privado para satisfacer sus necesidades -normalmente transicionales- de acceso a la vivienda.

Gráfico 2. Proporción representada por la tenencia en régimen de alquiler social para el conjunto de la población y para los jóvenes de entre 25 y 35 años de edad en diferentes países europeos.

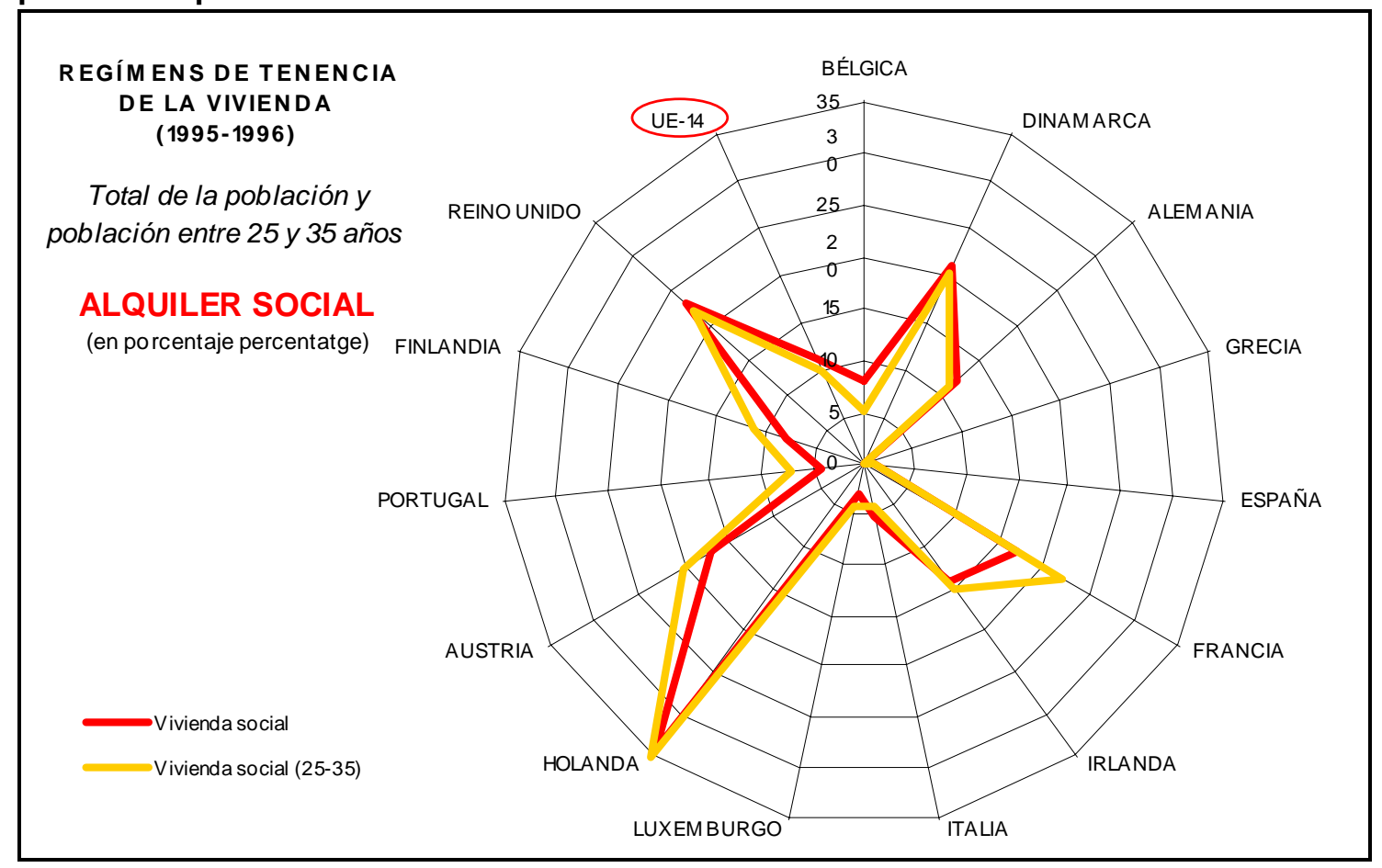

Fuente: Elaboración propia a partir de los datos del estudio Housing Conditions in Europe (Giorgi, et al): ECHP Wave 3 (1995 i 1996) y UDB Database 2/2002

A este respecto, Mulder (2006) afirma que las diferencias en cuanto a la edad de emancipación tienen bastante que ver con factores relativos al mercado inmobiliario, particularmente aquellos países de Europa donde la extensión de la tenencia en propiedad, la dificultad de acceso a las hipotecas y los elevados precios de la vivienda operan como factores combinados reduciendo el abanico de oportunidades al alcance de los jóvenes. Esta situación es común, aunque en diferentes grados, en el conjunto de los países del área mediterránea, caracterizados por la rigidez de sus mercados financieros e inmobiliarios (Italia, Grecia y España). Pero se hace particularmente patente en aquellos países en los que -como es el caso de España- la oferta de alquiler está muy por debajo de la que se estima como necesaria -y que Mulder situa entorno al $30 \%$ del total del parque inmobiliario- a los efectos de facilitar las transiciones juveniles y remover los obstáculos que se interponen a la movilidad de la fuerza de trabajo (Mulder, 2006; Mulder y Billari, 2006). 


\section{Qué políticas de vivienda? Políticas generales o específicamente dirigidas a los jóvenes?}

El universalismo implica el desarrollo de políticas públicas susceptibles de ir más allá de la atención a las necesidades particulares de colectivos específicos, ya sea por su situación particular de desventaja o por el hecho de pertenecer a una determinada franja de edad.

Por un lado, la atención a colectivos específicos en situación de desventaja -el asistencialismotiende a situar la intervención pública en los márgenes, atendiendo sólo a una minoría de la población. Así, al concentrar todos los esfuerzos sobre los individuos en situación de desventaja -en este caso, independientemente de su edad- se tiende a dejar de lado a colectivos tales como los jóvenes no emancipados y, por lo tanto, en alguna medida dependientes financieramente de la familia de origen (Avramov, 2006). Así, se hace ciertamente difícil, particularmente en lo que respecta a los jóvenes, establecer una barrera que distinga entre aquellos jóvenes "en desventaja" que necesitan apoyo por parte de la administración y aquellos otros que no. Dado que las fuentes de financiación juvenil son plurales, parece complicada la tarea de determinar el grado exacto de dependencia subyacente de cada joven así como la medida en que en unos u otros casos la familia presta apoyo financiero al proceso de emancipación (Chambaz, 2001; Patón Casas, 2003).

Por otro lado, la atención a los jóvenes como colectivo específico tampoco deja de plantearnos ciertas dudas. Así, si bien podemos identificar un conjunto de políticas que han de ser consideradas clave en la perspectiva de la emancipación y las transiciones juveniles -según hemos visto, las educativas, las laborales y las de vivienda- no se debería perder de vista que se trata de áreas de intervención pública nucleares también para la satisfacción de las necesidades sociales generales. Se puede argumentar pues, la no existencia necesidades juveniles que precisen de atención específica desde las políticas sociales o de vivienda. Y parece legítimo defender, por lo tanto, que las oportunidades para la emancipación de las personas jóvenes sean proporcionadas universalmente por el sistema de bienestar, mediante políticas sociales y de vivienda desarrolladas con relativa independencia respecto de la edad de las personas; atendiendo, si cabe, a la manera particular en que las diversas necesidades se expresan para las diversas categorías sociales y de edad.

Ciertamente, se pueden tener presentes las necesidades juveniles dentro del conjunto de necesidades que de hecho son comunes y universales para todas las personas, siendo en este caso paradigmáticas las políticas de acceso a la vivienda. Y por supuesto no es lo mismo desarrollar una política juvenil de vivienda -esto es, específicamente diseñada al efecto de facilitar las transiciones juveniles y avanzar los procesos de emancipación- que tener en cuenta las necesidades de los jóvenes en la programación de intervenciones públicas generales de carácter tendencialmente universal. Es claro en este sentido, tal y como ya hemos visto, que la vivienda de alquiler se ajusta bien -en principio y en general- a las necesidades de los jóvenes, que en gran medida derivan del carácter transicional de su estatus. Pero en ningún caso cabe perder de vista que este régimen de tenencia responde simultáneamente a las necesidades de convivencia provisional de otros grupos sociales, no necesariamente jóvenes: personas divorciadas, hogares monoparentales, personas en situación de movilidad laboral, etcétera. De hecho, desde el momento en que el desarrollo de la vida familiar ya no es lineal, estas convivencias provisionales han ido en aumento, aunque de forma muy desigual, en toda Europa. Coherentemente, parece clara la necesidad de buscar un equilibrio en los regímenes de tenencia -propiedad, alquiler privado y alquiler social- de tal manera que se pueda 
responder adecuadamente a las necesidades del conjunto de la ciudadanía (Trilla, 2001; Mulder, 2006).

Podemos hacer referencia aquí, como ejemplo, a la gran extensión relativa que el alquiler tiene en Suiza o Alemania. En este sentido, la situación de los jóvenes alemanes o suizos en relación con la vivienda es claramente mejor a la de -por ejemplo- los jóvenes italianos o españoles, que no encuentran hoy en día una oferta de alquiler suficientemente amplia y adaptada, por lo tanto, a las necesidades que surgen de los procesos de transición juvenil. Pero, además, tanto en Suiza como en Alemania -y esto es lo que nos interesa destacar aquí ahora, el régimen de tenencia en alquiler se extiende a todas las edades -no sólo a los jóvenes- aunque de hecho sean los jóvenes los que recurren en mayor medida (véase Gráfico 1 y Gráfico 2). Alemania y Suiza constituyen pues un buen ejemplo de cómo una determinada política global de vivienda -esto es, el fomento generalizado del alquiler- puede satisfacer las necesidades juveniles sin recurrir al diseño de políticas específicas. Otro ejemplo, también dentro del área de los países de Europa central, es Austria. Este país, que presenta una cobertura de vivienda social muy por encima de la media europea, no lleva a cabo políticas de vivienda social específicamente dirigidas a los jóvenes, aún cuando éstos resultan estar cubiertos por la vivienda social en mayor medida que el conjunto de la población de su país (véase Gráfico 1). Y si bien la política austriaca de vivienda social no se focaliza específicamente sobre los jóvenes, responde bien a sus necesidades transicionales debido a la amplia extensión de la oferta de vivienda en alquiler, tanto privado como social. En general, en países como Holanda, Alemania o Austria, el alquiler -tanto el público como el privado- es percibido como una alternativa satisfactoria, que no da lugar a la estigmatización social de quienes recurren a ella. Y la alternativa del alquiler privado está suficientemente protegida por regulaciones estatales que aseguran la posición de los inquilinos, tendiendo todo ello facilitar la emancipación residencial de las personas jóvenes aún cuando estos no sean destinatarios privilegiados de las políticas de vivienda.

En el otro lado, tenemos el caso de los países del área mediterránea. En España, por ejemplo, la acusada falta de viviendas de alquiler frena la movilidad de los jóvenes que buscan trabajo y obliga a las parejas jóvenes -habiéndose garantizado previamente dos salarios- a convertirse en propietarios (Trilla, 2001). Hemos visto ya cómo, en general, las dificultades de emancipación juvenil -y, por lo tanto, la independización residencial tardía- se da sobretodo en aquellos países dotados de un sistema de bienestar que deposita la responsabilidad en la satisfacción de las necesidades sociales principalmente sobre la familia, en el que se ofrece un abanico limitado de prestaciones sociales públicas y en el que establece una regulación del mercado laboral con la que se favorece la precariedad laboral y la inestabilidad en el empleo. La combinación de estos factores con el tipo de régimen de propiedad que es dominante -esto es, la amplia extensión de la propiedad y el difícil acceso a los préstamos hipotecarios-, así como la virtual inexistencia de una oferta pública de alquiler social o de alternativas para el alojamiento temporal de los estudiantes- sitúa el retardo en la emancipación juvenil como uno de los principales problemas sociales y como una de las prioridades de intervención pública en materia de vivienda. La pregunta subsiguiente ante un panorama como este, es qué políticas de vivienda cabe poner en marcha para facilitar la independencia residencial y promover una emancipación juvenil más temprana. Y si estas políticas han de desarrollarse, o no, en base a la articulación de medidas específicamente dirigidas a los jóvenes.

A este respecto, y en lo que se refiere a España, Consejo Económico y Social (CES, 2002), ha propuesto un conjunto de medidas susceptibles de mejorar las condiciones de emancipación 
de las personas jóvenes. La mayoría de estas propuestas contemplan intervenciones de carácter general y sólo algunas de ellas se dirigen específicamente a los jóvenes. Aún así, tanto las unas como las otras responden bien, en general, a las conclusiones que cabe extraer del análisis transnacional de los procesos de emancipación juvenil y del estudio de las causas de la heterogeneidad en cuanto al momento en que los jóvenes de los diferentes países acceden a la independencia residencial. Se trata, en todos los casos, de medidas objetivas que tienden a promover, por sí mismas, una ampliación en el marco de oportunidades al alcance de los jóvenes; y que, por lo tanto, son de aplicabilidad en todos aquellos países -en particular los del área mediterránea- en los que la emancipación juvenil es más tardía y donde los jóvenes se encuentran limitados en cuanto a su capacidad de optar, tanto en lo que se refiere a la forma de tenencia como en lo que se refiere a la tipología de los inmuebles.

Las medidas de carácter general de mayor relevancia para los jóvenes -aún sin aparecer como específicamente juveniles- tienen que ver con el incremento del gasto público en política de vivienda, con la promoción de alquiler social hasta su equiparación con el resto de países de la UE y con la potenciación de la vivienda en alquiler privado. El CES propone promover el alquiler privado mediante la implantación de ayudas directas y medidas fiscales de apoyo a los inquilinos, mediante la penalización fiscal de las viviendas desocupadas y mediante la utilización de la rehabilitación de inmuebles como instrumento para promover su entrada en el mercado inmobiliario del alquiler. La mayoría de estas propuestas tienen que ver con las dificultades de acceso que son consecuencia de la falta de pluralidad en las formas de tenencia que se hacen accesibles a los jóvenes; y tienden pues a responder a las necesidades juveniles transicionales, facilitando su independización residencial. Otras propuestas de carácter general -en este caso, más indirectamente relacionadas con las necesidades transicionales de los jóvenes- tienen por objetivo la mejora de la oferta inmobiliaria general mediante la introducción de medidas para facilitar el control de la oferta y promover la eficacia y la transparencia de los mercados.

De entre las medidas propuestas por el CES cabe referirse también a aquellas que expresamente se dirigen a los jóvenes. Estas tienen que ver con la orientación de las políticas de juventud a la que más arriba nos hemos referido como de transición afirmativa, esto es, con las políticas que tienen en cuenta la ampliación del marco de oportunidades de los jóvenes facilitando el desarrollo de trayectorias de transición diversificadas a partir de modelos alternativos de vida, de convivencia y, en su caso, de formación familiar. En este ámbito se proponen dos tipos medidas: Las primeras se refieren a la tipología de vivienda que se les hace accesible; y las segundas vienen a dar respuesta a las dificultades de acceso específicamente relacionadas con el hecho de ser joven. Entre las primeras, se contempla la promoción de fórmulas de alojamiento alternativo, tales como apartamentos con servicios comunes y diversas fórmulas de alojamiento colectivo temporal, como las residencias de estudiantes. Dentro del segundo grupo de medidas se propone, por un lado, promover la mediación entre los propietarios de viviendas desocupadas, los jóvenes inquilinos, las compañías aseguradoras y las entidades financieras; $y$, por otro, garantizar un aval público de las operaciones de compra de vivienda por parte de los jóvenes, facilitando así el acceso a los créditos hipotecarios. Cabe destacar la importancia otorgada a la necesidad de facilitar el acceso de los jóvenes también a la vivienda en propiedad, puesto que se trata de una alternativa más de entre las que contribuyen a ampliar el abanico de oportunidades, fomentando así la diversidad de las formas de emancipación. 
Finalmente, no hay que perder de vista el hecho de que, aún cuando las medidas propuestas por el CES son recomendaciones referidas casi en exclusiva a las políticas de vivienda, éste identifica y se refiere también la situación del mercado laboral español como factor determinante de las dificultades de emancipación juvenil y de la prolongación de la dependencia respecto del hogar familiar de origen. Así, la dificultad de acceso al mercado inmobiliario y el retraso en la independización residencial se dan en un contexto en el que la situación laboral de los jóvenes se caracteriza por la temporalidad, la precariedad laboral y el desempleo.

\section{Recapitulación y conclusiones}

La idea de juventud, como demuestra el modelo nórdico de bienestar, no tiene porqué verse siempre asociada con la precariedad de un proceso de transición largo, traumático y costoso hacia la plena ciudadanía. No cabe duda alguna, en este sentido, relativa a la centralidad de los sistemas de bienestar en cuanto se refiere a las transiciones juveniles. Los sistemas de bienestar son explicativos, al menos, de las diferencias entre aquellos países en los que la emancipación se produce más tarde -modelo mediterráneo familiarista- y en los que se produce a edades más tempranas -modelo socialdemócrata y universalista nórdico.

Aún así, es preciso tener en cuenta que la emancipación juvenil depende de una gran multiplicidad de factores y circunstancias que se interrelacionan de un modo complejo y que apuntan al conjunto de las políticas sociales $-y$ al grado de coordinación entre todas ellascomo el máximo responsable de las diferencias en cuanto a las edades de emancipación en los diferentes países de Europa. Las políticas de mercado laboral -los niveles salariales y sobretodo la estabilidad en el empleo- juegan un papel determinante sobretodo en los países del área mediterránea, puesto que de ellas dependen las posibilidades de acceso al régimen de tenencia en propiedad. Asimismo -tal y como ocurre los casos de Francia y Holanda- desde las políticas educativas se pueden ofrecer a los estudiantes alternativas de alojamiento colectivo y temporal, promoviendo las residencias estudiantiles como instrumento para favorecer una emancipación juvenil temprana, aún no formando parte de las políticas de vivienda propiamente dichas. Sin embargo, las formas de alojamiento colectivo y temporal, no tienen porqué ser necesariamente vinculadas a la condición de estudiantes. Como alternativa de alojamiento provisional, se ajusta a cualesquiera otras circunstancias vitales derivadas del carácter transicional de la condición juvenil.

Aún reconociendo la centralidad de los sistemas de bienestar, existe siempre, sin embargo, un espacio para el desarrollo autónomo de determinadas áreas de las políticas públicas y sociales. Esto implica la existencia de margen suficiente para que las políticas de vivienda impacten, por sí mismas, sobre la edad en la que los jóvenes acceden a la independencia residencial respecto del hogar familiar de origen. Los regímenes de propiedad de la vivienda, el peso relativo del alquiler o la extensión de la vivienda social aparecen como factores clave, explicativos en gran medida de las diferencias en cuanto a la edad de emancipación en los diferentes países de Europa. Las políticas de vivienda, al ofrecer a los jóvenes un espacio para su desarrollo autónomo, contribuyen a favorecer al ejercicio de los derechos de ciudadanía que les son reconocidos formalmente a partir de la mayoría de edad.

La capacidad para el ejercicio efectivo de los derechos de ciudadanía define el marco de oportunidades en el que surgen y se desarrollan las expectativas juveniles, por lo que la remisión a las predisposiciones culturales de los jóvenes o de sus familias como explicativas de 
las diferentes pautas de comportamiento en los procesos de transición a la vida adulta parece del todo incompleta $y$, en nuestra opinión, contribuye a oscurecer la comprensión del fenómeno. Así, si bien es cierto que los regímenes de bienestar surgen y se desarrollan en -y a partir de- un determinado contexto cultural, también lo es que la distribución de responsabilidades para la satisfacción de las necesidades sociales -esto es, la presencia de sistemas de bienestar basados predominantemente en el estado, en el mercado o en la familiajuegan sin duda un papel relevante -junto con las políticas sociales sectoriales- en la consolidación o modificación de las pautas culturales y de comportamiento de los jóvenes y de sus familias.

Focalizar nuestra atención sobre las oportunidades de emancipación nos ha permitido abordar con mayor claridad los procesos de emancipación juvenil. Desde el momento en que la ampliación en el marco de oportunidades es un hecho objetivo -independiente como tal de la medida y la forma en que pueda ser aprovechado por los jóvenes o por sus familias- nos facilita las comparaciones transnacionales haciendo abstracción, por completo, de las predisposiciones sociales o culturales previas. Así, la existencia de una amplia oferta de vivienda social o la mayor extensión relativa del alquiler -pero también las transferencias sociales y los salarios diferidos bajo la forma de prestación de servicios, por ejemplo para estudiantes- contribuyen a ampliar las oportunidades de acceso a la vivienda por parte de los jóvenes. Y la existencia de una oferta inmobiliaria diversificada en cuanto a tipología -espacio, equipamientos, servicios comunes, etcétera- tiende a su vez a facilitar la elección de formas alternativas de alojamiento, convivencia u organización familiar por parte de los jóvenes.

\section{Bibliografía}

Aasve A.; Billari F.C.; Ongaro F. (2000), "The impact of income and employment status on leaving home: Evidence from the Italian ECHP Simple", en MPIDR Working Papers, n. 2000012. Rostock: Max Planck Institute for Demographic Research.

Disponible en línea:

http://www.demogr.mpg.de/Papers/Working/wp-2000-012.pdf

Aasve A.; Billari F.C.; Mazzuco, S.; Ongaro F. (2001), "Leaving home ain't easy. A comparative longitudinal analisis of ECHP data" en MPIDR Working Papers, n. 2001-038. Rostock: Max Planck Institute for Demographic Research.

Disponible en línea:

http://www.demogr.mpg.de/Papers/Working/WP-2001-038.pdf

Avramov, D. (2006), "The housing dimensions of population change and welfare reforms", ponencia presentada en la conferencia Housing in an expanding Europe: theory, policy, participation and implementation, 2-5 de julio de 2006, Lubiana: EHNR

Disponible en línea:

http://enhr2006-ljubljana.uirs.si/publish/PIV dragana.pdf

Billari, F. (2004), "Becoming adult in Europe: A micro/macro-demographic perspective", Demographic Research, Special Collection 3, Article 2. Rostock: Max Planck Institute for Demographic Research.

Disponible en línea: 
http://www.demographic-research.org/special/3/2/S3-2.pdf

Billari, F.C; Wilson, C. (2001), "Convergence towards diversity? Cohort dynamics in the transition to adulthood in contemporary Western Europe" en MPIDR Working Papers, n. 2001039. Rostock: Max Planck Institute for Demographic Research.

Disponible en línea:

http://www.demogr.mpg.de/Papers/Working/WP-2001-039.pdf

Billari, F.C; Philipov, D.; Baizán, P. (2001), "Leaving home in Europe: the experience of cohorts born around 1960", en MPIDR Working Papers, n. 2001-14. Rostock: Max Planck Institute for Demographic Research.

Disponible en línea:

http://www.demogr.mpg.de/Papers/Working/wp-2001-014.pdf

Blok, H.; Feijter, H. (1997), "Youth Homelessness in the Netherlands. Nature, policy, good practices". Documento de trabajo elaborado para el Amsterdam Study Centre for the Metropolitan Environment. Amsterdam: University of Amsterdam.

Disponible en línea:

http://www.feantsa.org/files/national reports/netherlands/netherlands 1996.pdf

Chambaz, C. (2001), "Les jeunes adultes en Europe: indépendance résidentielle, activité, ressources" en Recherches et Prévisions, n. 65, pp. 53-71, París: Caisse Nationale des allocations familiales.

Disponible en línea :

http://www.cnaf.fr/

Clapham, D. (2006), "Identity and lifestyle in housing research", ponencia presentada en la conferencia Housing in an expanding Europe: theory, policy, participation and implementation, 2-5 de julio de 2006, Lubiana: EHNR

Disponible en línea:

http://enhr2006-ljubljana.uirs.si/publish/w08 Clapham.pdf

Corijn, M. (1999), "Transitions to adulthood in Europe for the 1950s and 1950s

cohorts" en CBGS-Werkdocuments, n. 4, Bruselas: CBGS

Disponible en línea:

http://www-les-lundis.ined.fr/textes/MartineCorijn.pdf

Consejo Económico y Social (2002), Estudio sobre la emancipación de los jóvenes y la situación de la vivienda en España, Informe 3/2002, Madrid: CES

Disponible en línea:

http://www.ces.es / http://www.inmobiliaria-uam.com/fileadmin/Documentos/Informe CES.pdf

Ermisch, J.F (1997), "Prices, Parents and Young People's Household Formation", en ISER Working Paper Series, n. 1997-18, Essex: Institute for Social and Economic Research.

Disponible en línea:

http://www.iser.essex.ac.uk/pubs/workpaps/pdf/1997-18.pdf 
Esping-Andersen, G. (1993), Los tres mundos del Estado de Bienestar. Valencia: Alfons el Magnànim.

Flaquer, L. (2004), "La articulación entre familia y el Estado de bienestar en los países de la Europa del sur", en Papers, n. 73, pp. 27-58, Bellaterra: Universitat Autònoma de Barcelona Disponible en línea: http://ddd.uab.es/pub/papers/02102862n73p27.pdf

Giorgi, L.; Kofler, A.; Avramov, D. (2001), "European Housing Policies Compared", documento de trabajo elaborado para el grupo de investigación IMPACT: The housing dimension of welfare reform, Viena: The Interdisciplinary Centre for Comparative Research in the Social Sciences Disponible en línea:

http://www.iccr-international.org/impact/docs/giorgi-kofler.doc

Golsch, K. (2002), "Employment flexibility in Spain and its impact on transitions to adulthood" en Papers de Demografia, n. 208, Barcelona: Centre d'Estudis Demogràfics

Disponible en línea:

http://www.ced.uab.es/publicacions/PapersPDF/Text208.pdf

Hoekstra, J. (2006), "High vacancy rates and high house prices: a Mediterranean paradox", ponencia presentada en la conferencia Housing in an expanding Europe: theory, policy, participation and implementation, 2-5 de julio de 2006, Lubiana: EHNR

Disponible en línea:

http://enhr2006-liubljana.uirs.si/publish/W21 Hoekstra-Vakili\%20Zad.pdf

Jacob, M.; Kleinert, C., (2007) "Does unemployment help or hinder becoming independent? The role of employment status for leaving the parental home" en IAB Discussion Papers, n. 5, Nuremberg: Institute for Employment Research (IAB)

http://doku.iab.de/discussionpapers/2007/dp0507.pdf

Jurado Guerrero, T. (2003). "La vivienda como determinante de la formación familiar en España desde una perspectiva comparada", en Revista Española de Investigaciones Sociológicas (REIS), n. 103, pp 113-157, Madrid: Centro de Investigaciones Sociológicas (CIS) Disponible en línea:

http://www.reis.cis.es/reis/pdf/reis 103 061167997363305.pdf

Laaksonen, H. (2000), "Young adults in changing welfare status. Prolonged transitions and delayed entries for Under-30s in Finland, Sweden and Germany in the "90s", documento de trabajo elaborado para el Mannheimer Zentrum für Europäische Sozialforschung, Mannheim: MZES

Disponible en línea:

http://www.mzes.uni-mannheim.de/publications/wp/wp-12.pdf

Martins, N.; Villanueva, E. (2006), "Does limited access to mortgage debt explain why young adults live with their parents?", documento de trabajo presentado en el Finance and Consumption Workshop: Consumption and Credit in Countries with Developing Credit Markets, Florencia, 16-17 de junio de 2006 
Disponible en línea:

http://www.iue.it/FinConsEU/ResearchActivities/DevelopingCreditJune2006/martins villa cores. $\underline{\mathrm{pdf}}$

Mayer K.U. (2001), "The paradox of global social change and national path dependencies: life course patterns in advanced societies", en Woodward, A.E, y Coolí, M. (ed), InclusionsExclusions. pp. 89-110, Londres: Routledge

Disponible en línea:

http://www.mpib-berlin.mpg.de/en/institut/dok/full/Mayer/theparad/Woodward Kohli eForm.pdf

Moreno Minguez, A. (2005), "The persistence of male breadwinner model in southern European countries in a compared perspective: Familism, employment and family policies", en Marie Curie Fellowship Association Annals, Volumen IV, Bruselas: MCFA

Disponible en línea:

http://www.mariecurie.org/annals/volume4/soc1.pdf

Mulder, C.H (2006), "Housing and population: A two-sided relationship", en Demographic Research, Volume 15, Article 13, pp 401-412. Rostock: Max Planck Institute for Demographic Research.

Disponible en línea:

http://www.demographic-research.org/volumes/vol15/13/15-13.pdf

Mulder, C.H; Billari, F.C. (2006), "Home ownership regimes and lowest-low fertility", documento de trabajo presentado para el encuentro Home ownership in Europe: policy and research issues, Delft: 23-24 de noviembre de 2006

Disponible en línea:

http://www.tudelft.nl/live/binaries/72d39530-86ea-4a35-8768a67e45b91c94/doc/Mulder\%20and\%20Billari.pdf

Mulder, C.H. (2000), "Leaving home in the Netherlands: when and in which housing", documento de trabajo presentado para el workshop Leaving home: A European Focus. Rostock: 6-8 de septiembre de 2000

Disponible en línea:

http://www.demogr.mpg.de/Papers/workshops/000906 paper06.pdf

Patón i Casas, J.M. (2003), Joves adults i polítiques de joventut a Europa. Barcelona: Secretaria General de Joventut.

Disponible

en

línea:

http://www6.gencat.net/joventut/catala/sgi/observatori/publicacions/estudis15.htm

Toussaint, J.; Elsinga, M. (2006), "The meaning of housing tenure in eight European Countries". en Elsinga, M. (Ed.), Home ownership in Europe; policy and research issues, pp. 115. Delft: ENHR

Disponible en línea (borrador):

http://www.tudelft.nl/live/binaries/72d39530-86ea-4a35-8768-a67e45b91c94/doc/Toussaint.pdf

Trilla, C. (2001), La política de vivienda en una perspectiva europea comparada, Barcelona: Fundació La Caixa 
Architecture, City, and Environment
Arquitectura, Ciudad y Entorno

Disponible en línea:

http://obrasocial.lacaixa.es/estudiossociales/vol09 es.html 
Architecture, City, and Environment

Arquitectura, Ciudad y Entorno 